(n)

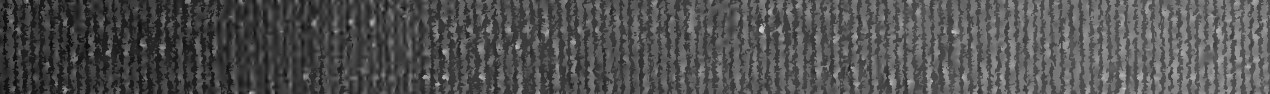
15: 15.5. 156) 116) 3:5

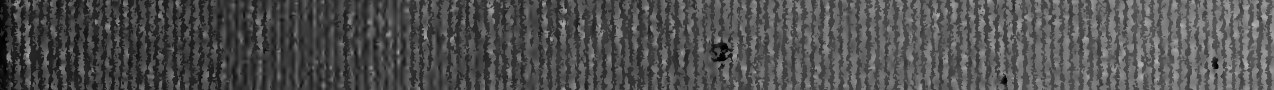
1310)

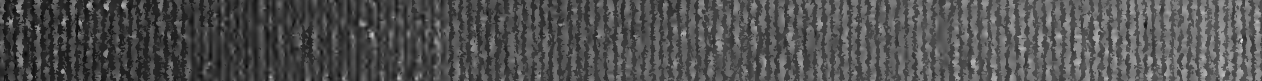

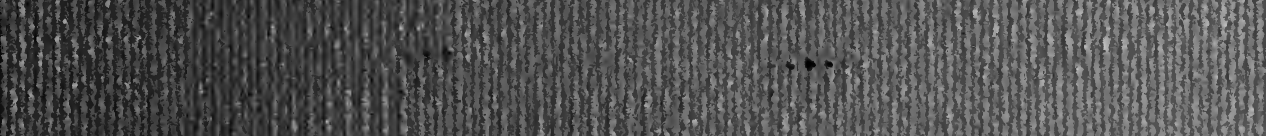
tom 1) H. 162. WII

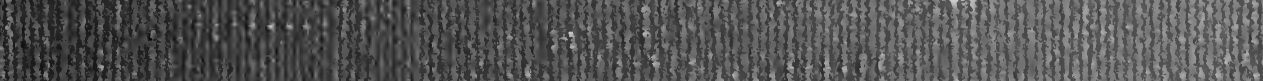

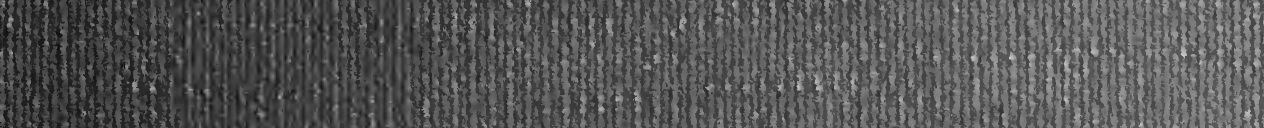
in 4.5.5.

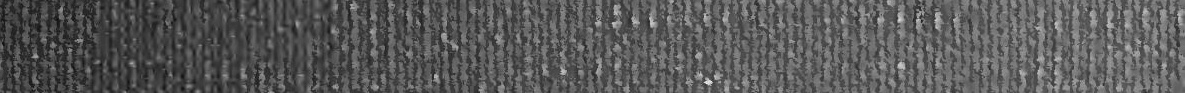
H.t. 6.

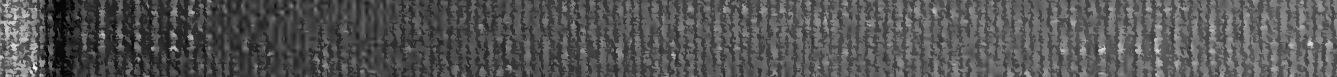







NATURAL LAW IN SCIENCE AND PHILOSOPHY 



\title{
NATURAL LAW
}

\author{
IN
}

\section{SCIENCE AND PHILOSOPHY}

\author{
By \\ EMILE
(Member of the Academy)
}

Authorized Translation by

F R E D R O T H W E L L

NEW YORK

THE MACMILLAN COMPANY

I9I 4 


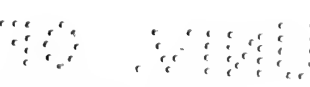

कालमा 


\section{PREFACE BY THE AUTHOR}

MORE than twenty years have elapsed 1 since these lessons were delivered at the Sorbonne. In the interval, science has advanced with giant strides; and there can be no doubt but that I should have to examine many a scientifico-philosophical theory of which this work makes no mention, were I now to recommence the course I then gave. All the same, I do not think that the problem raised in my classes during the session I892-3 has been solved or that it has ceased to elicit the keenest interest. Our object is to discover whether the idea of natural law is the same for the scientist as it is for the philosopher.

Science proposes to explain things scientifically. And, in these days more especially, the concept of scientific explanation has received precise definition. It comprises neither the knowledge of the intrinsic nature of things, nor that of their origin or value. 
NATURAL LAW IN SCIENCE AND PHILOSOPHY

It implies the possibility of extracting, from the given reality, sensibly constant rapports, and it declares that such a rapport is explained, when it has been possible to reduce it to some other rapport already known and recognized as permanent and general. Science is reduction. Mathematics is its ideal, its form par excellence, for it is in mathematics that assimilation, identification, is most perfectly realized. The universe, scientifically explained, would be a certain formula, one and eternal, regarded as the equivalent of the entire diversity and movement of things.

The philosopher asks himself whether natural law as assumed by science, wholly coincides with law as really existing in nature ; whether science and reality are so alike that science may be regarded, as exhausting everything intelligible and true that the real contains.

The theory upheld in the present work is that no absolute coincidence exists between the laws of nature as science assumes them to be, and the laws of nature as they really are. The former may be compared to laws proclaimed by a legislator and im- 
posed $\ddot{a}$ priori upon reality. The latter are harmonies towards which we ascertain that the actions of different beings really tend. The former are abstract rapports, the elements of which are themselves rapports; the latter are concrete rapports, the terms of which are real subjects, true beings.

Now, the doctrine here set forth consists in regarding scientific intelligibility as the most objective form, but not as the sole type, of intelligibility. Science acquires that perfection which characterizes it, by setting aside, sending about their business,

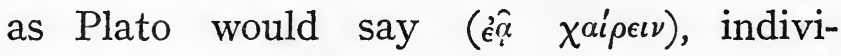
duals, natural beings. The philosophy with which our doctrine is connected admits that between individuals themselves, between concrete realities as such, there may be found relations which, though they cannot be reduced to mathematical relations, nevertheless exhibit a certain order which satisfies the intelligence. There exist intelligible relations other than those of reducibility and identity: it is the purpose of philosophy to reveal and define such relations. In Plato, for instance, we have the commonalty, or mutual participation 
NATURAL LAW IN SCIENCE AND PHILOSOPHY

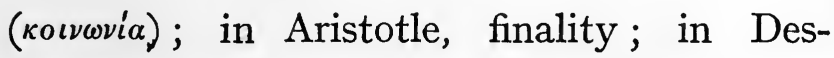
cartes, evident connexion ; in Leibnitz, harmony; and in Hegel, rational synthesis. Thus, philosophy both widens and renders flexible-without destroying - the concept of intelligibility.

The present doctrine regards as both contingent and intelligible those relations between beings that it discovers in the relations between relations; it sees in the mechanically necessary rapports implied by science, an abstraction, that consists in isolating the relations from their living subjects, and looking upon them as self-sufficient. In the reality of things, the rigid, eternal, . mathematical order, which science considers from its own point of view, serves to obscure an order that is invisible, supple and untrammelled, and therefore all the more beautiful :

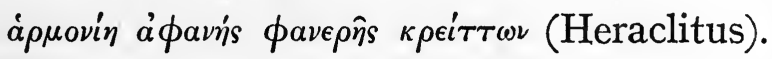

EMILE BOUTROUX. 


\section{Contents}

Preface by the Author. $\quad$. $\quad$. 5

I

The Problem of the Meaning of Natural LAWS

II

The Logical Laws

- $2 \mathrm{I}$

III

The Mathematical Laws

\section{IV}

The Mechanical Laws

\section{$\mathrm{V}$}

The Mechanical Laws (continued) • • . 6I

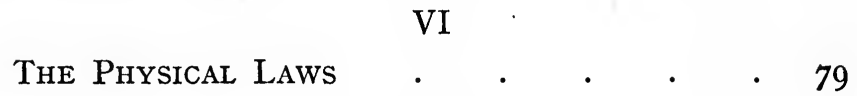

The Chemical Laws · $\quad \cdot \quad \cdot \quad \cdot \quad \cdot 94$

VIII

The Biological Laws

VII 


\section{CONTENTS}

\section{IX}

PAGE

The Biological Laws (continued) . . . . I27

$\mathrm{X}$

The Biological Laws (continuation and end). I43

\section{XI}

The Psychological Laws

\section{XII}

The Psychological Laws (continuation and end) I75

XIII

The Socrological Laws.

. ${ }^{2} 58$

tinuation and end) 


\section{NATURAL LAW IN \\ SCIENCE AND PHILOSOPHY}

I

THE PROBLEM OF THE MEANING OF NATURAL LAWS

$\mathbf{T}^{\mathrm{T}}$ is our purpose to study the idea of 1 natural law as presented in modern times, to interpret it philosophically and determine its metaphysical and moral signification. In order to state the problem with the requisite precision, we shall rely on the results of the speculations of the seventeenth and eighteenth centuries,- - speculations closely connected with the development of modern science.

Bacon and Descartes, the founders of modern philosophy, regarded science as having, for its object, to arrive at laws which should possess the dual characteristic of 
NATURAL LAW IN SCIENCE AND PHILOSOPHY

universality and reality. It was the ambition of both, in spite of appearances which are often wrongly interpreted, to supersede the ancient point of view, in accordance with which, laws were only general and ideal, to rise beyond the probable and the possible, and to obtain a sure knowledge of the real. But though their object is identical, their methods of attaining it are different: Bacon takes the path of empiricism; Descartes that of rationalism.

The Cartesians consider that it is possible to find the principles of universal and real laws in certain mental operations, which have not yet been sufficiently investigated. Descartes analyses the matter immediately given, i.e. ideas, and in them finds elements the specific characteristic of which is that they are obvious when compared with intellectual intuition. These elements, according to him, are the principles sought after. And, indeed, they seem calculated to supply universal laws; but as it is from the mind that they have been drawn, will they allow of real laws being discovered? This is the problem with which Descartes is immediately confronted. In his Cogito, ergo sum, what 
is the meaning of ergo? Even now it is no easy matter to connect personal existence with the Cogito? But the existence of God, and in particular of things corporeal, will call for a real deduction, one of ever increasing complexity. After Descartes, Malebranche considers it necessary to distinguish the laws of action or of existence from those of essence; and so he conceives his theory of occasional causes. Spinoza proves that a similar distinction may be drawn between internal and external causality; he endeavours to connect the laws of existence with those of essence. According to Leibnitz, these various systems cannot supersede possibility. It is indispensable that a new principle, equally absolute, the principle of sufficient reason, be added to that of contradiction, the only one with which they are acquainted. This will be the distinctive principle of the real. Again, deep within existing things, separations become marked. Everything is not reducible to mathematical order; substances govern it; and in this higher order, we must consider, on the one hand, physics, the domain of efficient causes, and on the 
other hand, ethics, the domain of final causes. In the case of Kant, these distinctions become separations, which, to us, are radical and absolute. Again deep within the real world and coming between the physical and the moral laws, he sets up the biological laws, which, to our mind, at all events, are incapable of being reduced to the former, and presuppose finality. And lastly, Schelling and Hegel $\checkmark$ regard the laws of essence and of existence as inadequate: to account for the real, we must posit laws of development, determine a process which precedes all essence and all existence alike, and is the reproduction, in thought, of the very creation of things.

Thus, rationalistic philosophy, starting with unity, has found itself compelled to recognize different types of laws. It has been confronted with experience, and, when its principles have been compared with facts, has been forced to enlarge its scope. Truth to tell, rationalistic philosophy expected to reduce this diversity and make it intelligible. Only apparently, however, and by continually modifying the concept of intelligibility, did it effect this. 
Descartes, by his intuition, actually modifies the idea of intellectualism which the ancients had set up. Spinoza places in the foreground a new notion, that of the infinite, which the ancients regarded as the very essence of unintelligibility. Leibnitz boldly affirms the actual realization of this infinite. Kant effects a revolution in the doctrine of intelligibility by recognizing two kinds of logic: the old logic of Aristotle, which is purely formal and incapable of establishing anything; and transcendental logic, which proceeds by synthetic judgments à priori. Finally, Schelling and Hegel, who even affirm the identity of contradictories, openly reject the standpoint of the old logic. The latter, then, has been regarded as inadequate to explain existence, and intellectualism has almost been compelled to abrogate it entirely, in attaining to a comprehension of the real.

But, say the empiricists, what is the use of troubling about the $a$ priori principles of intellectualism? There is no need to depart from nature in order to understand her. Observation and induction, if properly applied, are sufficient to realize the modern 
NATURAL LAW IN SCIENCE AND PHILOSOPHY

idea of science. Still, a difficulty here arises, the very opposite of that which the rationalists encountered. In the case of Descartes, the problem was to link on the real to the universal ; the problem for Bacon is to link on the universal to the real. The latter philosopher, indeed, looks upon the mind as absolutely passive; or rather, in order to establish science, the mind must make itself truly passive, a veritable tabula rasa on which the events of the outer world are impressed. Bacon, however, besides being still embarrassed by the scholastic conception of quality, rather expresses a desideratum than demonstrates the possibility of realizing valid inductions. Locke clearly sees that the thing which needs explanation is the connexion of ideas; he maintains that we connect our ideas by means of faculties innate within ourselves. Mere passiveness is inadequate as an explanation: experience traces innumerable characters on a tabula rasa; but the soul, of itself, unites together the simple ideas with which this external influence supplies it. Still, of what worth are laws thus created by human faculties? What sort of universality 
can they claim? Hume comes along and explains that we have, deep within ourselves, the power to join together the ideas of phenomena in relations of resemblance, contiguity and causality. As regards causality, which, of itself, would never obtrude upon us, habit replaces the intuition lacking, makes association practically indissoluble, and so inclines us to look upon the laws of nature as really universal and necessary.

Therefore, just as intellectualism, in order to comprehend reality, has had to extend and perhaps to violate its principle, so also empiricism, to attain to universality, has found itself compelled to deviate from its original direction, either by recognizing, with Locke, mental faculties that cannot be reduced to experience, or, as Hume does, regarding external laws as the result of internal laws, of innate potencies.

Thus it would appear very difficult for the human mind to conceive the laws of nature as being both universal and real at the same time. When we explain to ourselves universality, reality slips out of our grasp, and vice versa. Must we then conjoin rationalism and empiricism, purely and simply? The 
NATURAL LAW IN SCIENCE AND PHILOSOPHY

conjunction of these two opposite points of view will give only a juxtaposition, not a synthesis. Now, what to philosophy was only an ideal and a problem, has been realized by science, which has succeeded in effecting a union between mathematics and experience, and supplying laws that are both concrete and intelligible. Its method has been to try to discover an appropriate positive principle for each order of realities. Newton supplied the type of scientific explanation by basing celestial mechanics on the law of gravitation, which is radically distinct from purely geometrical laws. The sciences have thus been emancipated, one after the other; they have been set up as autonomous, with the aid of special principles regarded as irreducible; for instance, a distinction has been made between physical principles and those that are purely mechanical, between chemistry and physics, between vital properties and physical and chemical properties. No doubt attempts are made to liken every science, mutatis mutandis, to the mathematical sciences; but certain sciences are no longer looked upon as a mere extension of the, rest; the 
special sciences are allowed to have their own specific principles.

Therefore, in order to study the idea of natural law, we must start with the various sciences, at the same time appealing to philosophy for hints as to the manner of interpreting their principles and results. We will take the laws just as the sciences offer them, divided into distinct groups, study each group separately and ask ourselves questions regarding each of them :

I. Their nature.-How far and in what sense are these laws intelligible? Are there not differences in generality and complexity, or does the appearance of a new group really mark the introduction of a new principle which is philosophically irreducible?

2. Their objectivity.-Do we regard these laws as forming the substance of things, or do they govern only the mode in which phenomena appear? Are they true absolutely or only relatively? Are they elements or merely symbols of reality?

3. Their meaning.-Does determination really exist in nature, or does it simply represent the way in which we must connect things in order to make of them objects of thought? 


\section{NATURAL LAW IN SCIENCE AND PHILOSOPHY}

In this way, we shall attempt to answer, from the present-day standpoint, the old question as to whether there are things that depend on ourselves, whether we are really capable of acting, or whether action is pure illusion. 


\section{THE LOGICAL LAWS}

$7 \mathrm{HE}$ logical laws are those that govern 1 all scientific research. By logical laws we usually mean those of syllogistic logic, as formulated by Aristotle; but there are logical laws of a still more general nature, to wit, the three principles of identity, contradiction and excluded middle.

The principle of identity may be expressed thus: $A$ is $A$. I do not say Being, but simply $A$, i.e. anything whatsoever that is capable of being conceived; nor do I say $A=A$, for the sign $=$ is a mathematical sign, actually limiting the very relation which has to be established. The principle of identity, thus defined, represents the type of possibility. The principle of contradiction, on the other hand, represents the type of the false, of logical impossibility: its expression is $A$ is not- $A$. This affirma- 
tion is impossible, i.e. $A$ and not- $A$ cannot be presented or posited together. The principle of excluded middle means that there is no middle term between $A$ and not- $A$. It may be called the principle of indirect possibility, for the new element in what it enunciates is that if not- $A$ is excluded, $A$ is posited. Two negatives make an affirmative : such is the essence of this latter principle. Suppose there is a middle term between $A$ and not- $A$, this middle term will be both not- $A$ and not-not- $A$. Now, if not-not- $A=A$, the middle term will be both not- $A$ and $A$, which lands us in a contradiction. Just as the second principle prevents two contradictories from being posited together, so the third prevents them from being abolished together.

These strictly logical laws are intelligibility itself, they appear as the type of evidence; but, of themselves alone, they do not constitute the whole of logic. Ordinary, so-called syllogistic, logic, is not content with these three principles. Consider the principle of contradiction as formulated by Aristotle; it contains elements which, manifestly, are not included in the strictly logi- 


\section{THE LOGICAL LAWS}

cal laws. "It is impossible for one and the same thing to belong and not to belong to one and the same subject at the same time and in the same connexion." Pure logic does not say of what nature $A$ must be; whereas in the case of Aristotelian logic, $A$ is not anything whatsoever : it is concept, i.e. a determinate thing. Besides, the expressions: "at the same time and in the same connexion," are not found in the formulæ of pure logic, From this standpoint, let us examine concept, the arrangement of concepts into propositions and the arrangement of propositions into syllogisms.

What is concept? It is not absolute unity, for, in order to explain things, it must involve multiplicity. Nor is it absolute multiplicity, for it reduces diversity to unity. It thus represents a certain conjunction of elements of a certain nature, a relation not merely of homogeneity but of heterogeneity, at least relative, between modes of being.

Nor can proposition, any more than concept, be strictly conformable to the formula $A$ is $A . \quad A$ is $A$ teaches us nothing. Now, a proposition must always teach some- 
thing, and thus admit of the formula $A$ is $B$.

And, lastly, the reasoning which links propositions to one another is not an exact identity, either; it is to propositions what propositions are to concept. Thus, we have not simply deduced, from the laws of pure logic, matter appropriate to the application of these laws; we have composed the syllogism with the aid of the laws of pure logic and of a superadded matter.

Does this matter, at all events, exactly harmonize with the logical form supplied by the three fundamental principles? Can the pure logical form be applied to it without being weakened. The history of philosophy teaches us that Aristotelian logic has had many adversaries. The English school, for instance, regards it as a vain sport of the mind, and intellectualist philosophers, such as Herbart, make ineffectual attempts to establish logically the legitimacy of the idea of connexion. In syllogistic logic, there is something not only new, but also strange, when compared with pure logic.

Concept, in fact, must express a unity involving a multiplicity. But then, what idea are we to form of this conjunction? If we 


\section{THE LOGICAL LAWS}

say that multiplicity is potentially in concept, we introduce an element of obscurity. If we say that concept contains its parts as a vase contains whatever is put into it, we are the victims of a physical conception, we pre-suppose the confused idea of space. Frequently we think we form a clear idea of space because we reduce it to a collection of elements. But, when unity has vanished, concept is non-existent, and to bring reasoning to bear on facts themselves, as immediate matter, would imply the suppression of logic altogether.

And so judgment contains something obscure. What is the connexion it sets up between subject and predicate? Is it a relation of determination? For instance, does the judgment: Paul is a man mean that mankind is matter of which Paul is a specification? To understand judgment in this fashion is to relapse into the obscure metaphysical notions of potency and act, form and matter. Will it be urged that the predicate is analytically drawn out of the subject? But that is only a sensible image, obscure to the understanding.

Finally, syllogism also lends itself to objec25 
tions that have never been clearly refuted: either tautology or the vicious circle is the danger it has to face. All men are mortal: this major premise implies the conclusion. Every man is mortal: this expression, indeed, does away with the vicious circle; but the word Every (Tout), whether expressing a metaphysical essence or indicating the existence of a genus, raises insoluble difficulties. Speaking generally, syllogistic logic presupposes the distinction between the implicit and the explicit, a distinction which cannot be cleared up.

Not only, then, do the laws of syllogistic logic contain something more than do the laws of pure logic, they also deviate from them, to some extent.

What, now, is the origin of Aristotelian logic? This origin is not wholly a priori, since it cannot be resolved exactly into pure logic. Must we say, along with the empiricists, that it is wholly a posteriori? To maintain this doctrine is to affirm that, strictly speaking, there are no syllogistic laws, but only special laws applicable to future events, in so far as they are demonstrated by experience and induction. Such was the opinion of Stuart 


\section{THE LOGICAL LAWS}

Mill. Quite logically Herbert Spencer maintained that in reality there were only reasonings by analogy, and no syllogisms at all. And yet, the answer might be urged, this syllogistic exactly represents the reasoning process of reflective consciousness. Indeed, we cannot do without it; whatever we do, it is implied in every demonstration which carries conviction with it. It has not the full evidence of pure logic, though it shares therein; consequently, it is not wholly $a$ posteriori but seems rather a blend of a priori and $a$ posteriori. The human mind, we may say, bears within itself the principles of pure logic; but since the matter offered to it does not seem to conform exactly with these principles, it endeavours to adapt logic to things so as to interpret the latter in a way that approaches perfect intelligibility as nearly as possible. Syllogistic logic may therefore be regarded as a method, an ensemble of symbols by which the mind is rendered capable of thinking things, a mould into which it will introduce reality to make it intelligible. It is in this way that we would answer the question of the nature and degree of intelligibility of the logical laws. 
At first sight, it may appear useless to question the objectivity of these laws, for there is nothing that seems more certain, more beyond all dispute, than this objectivity. And yet logic has been attacked quite as frequently as it has been extolled. No doubt it is a grave reproach against a person to say that he is not logical; as a rule, we admire those who are capable of organizing a vast mass of material after the type of the principles of identity and contradiction. But then, at times, we blame those who are looked upon as stubbornly logical and systematical: every system, it is alleged, is artificial ; to try to find some shade of difference even at the risk of encountering contradiction, is the way to grasp reality. This divergence of opinions seems as though it might be explained by the distinction established above. Pure logical laws are indisputable, but they concern not at all-or but very slightly-the inner nature of things; the laws of syllogistic go deeper into the nature of things, but a certain amount of discretion must be used in applying them.

The former we regard as absolutely necessary: it does not lie within our power to 


\section{THE LOGICAL LAWS}

conceive of them as aught but purely subjective and unrealized by nature; we do not even see how experience could contradict them, since all they do is to declare that if something is, it is. But that which constitutes their strength also constitutes their weakness : they leave indeterminate the very things to which they apply. When I say, $A$ is $A$, I lay no prohibition upon myself from implying that $A$, in itself, is devoid of identity. We have therefore to discover whether the very nature of things also is in conformity with these principles. The Eleatics maintained that being, in effect, expresses identity, and is exempt from contradiction, but over against such a system the history of philosophy sets that of Hegel, who, on the other hand, regards contradiction and necessary strife as in the inmost nature of things. There is no difference between these two systems, as regards the laws of pure logic. They both conform to these laws. For Hegel did not say that, in stating a proposition, you could also state the contradictory proposition. He thought that if, in the formula $A$ is $A$, we replace $A$ by its real value, we have, from the very outset, being 
identical with non-being. Which is the true doctrine, the Eleatic or that of Hegel ? Neither of them, probably. At all events, it is not the consideration of logical laws in themselves, but only the consideration of the concrete laws of nature, that can teach us to what extent real beings essentially participate in identity and contradiction.

It is less hazardous and more customary to regard the laws of syllogistic as the expression of the universal conditions to which the laws of nature are subject. According to this view, dogmatists are inclined to assimilate logic to reality. They base their opinion on what they call the natural harmony between thought and things, a principle they look upon as necessary and innate. This principle, however, is nothing but a wish, a desire, a mere postulate. Moreover, even if it were certain, it would not guarantee the objectivity of syllogistic logic, if this latter, as we have endeavoured to show, is not thought itself but rather a misrepresentation of the principles of thought resulting precisely from the opposition between thought and things.

Must we then altogether renounce the 
objectivity of this logic, and, with the empiricists, maintain that there are only facts, and that these facts create within us habits, imperious enough, no doubt, but purely subjective? It would appear that the logical laws cannot be regarded as derived exclusively from experience: this latter presents no groupings analogous to concepts, and concept is not a tardy acquisition of the mind. In spite of a prejudice handed down to us from Locke, it is with general concepts that the child begins, and it is precisely the function of experience to contradict and break them up. Concept, then, originates in the mind. No doubt it is formed on the occasion of experience and with materials borrowed from experience, but it is the mind that forms it. Now, it is beyond dispute that our reasonings are susceptible of being in harmony with facts; when they are out of harmony, we do not consider that reasoning is a vicious instrument, but rather that we have insufficient data, that our field of operations is too limited. Consequently, things possess relations which, in a measure, correspond to syllogistic concatenation. In nature, there is something resembling classes of beings or species, and 
something resembling classes of facts or laws. Still, we cannot know, a priori, how far this condition is realized ; nothing but the development of science can tell us that. Perhaps the following is all we can conjecture a priori. Man, to all appearance, is not a monster in nature; the intelligence that characterizes him must bear some relation to the nature of beings in general. Therefore, at the root of things, there must be, if not an intelligence similar to the human, at all events properties and dispositions that bear some analogy with this intelligence. It is reasonable to admit in nature a sort of tendency towards intelligibility. If this be the case, reasoning represents a mode of interpretation, of interrogation which may legitimately be employed in dealing with nature.

What, now, is the signification of the logical laws? Logic, certainly, is the most perfect type of absolute necessity, but it offers a $\sqrt{ }$ minimum of objectivity. It governs the surface of things but does not determine their nature; it remains true, whatever be that nature. The necessity it implies will be safeguarded, even if beings are to be considered as endowed with spontaneity, even if beings 


\section{THE LOGICAL LAWS}

are free. It is an absolute master, though infinitely remote from ourselves; an insurmountable barrier, though between it and ourselves there is more space than we shall ever be able to compass.

If syllogism is, in reality, but a symbol invented by the human mind, it cannot be regarded as self-evident that the necessity, proper to it, is, in effect, found realized in things. This necessity is the relationship implied in the notions of species and genus. The special sciences alone will inform us if there are genera and species in nature. However, as man is not an empire within an empire, as not only are our reasonings successful, but it is natural that they should be successful, we have reason to infer that in things there is a tendency to order and classification, to the realization of species and laws. And so already we dimly foresee that in the being all around us there might exist a duality analogous to that which we acknowledge within ourselves. Besides intelligence, we possess a mass of faculties grouped under the heading of activity. Intelligence is the rule of activity; but we cannot say d priori how far activity realizes intelligence. Per- 
NATURAL LAW IN SCIENCE AND PHILOSOPHY

haps the same thing happens in nature. There is a principle of necessity, but this principle is only the rule, not the basis of things. The knowledge of particular laws alone will give us some idea as to how far necessity is realized. 


\section{THE MATHEMATICAL LAWS}

A FTER the logical laws, the mathemaA tical laws are those that appear most general. It would seem, at the outset, as if they, too, were perfectly clear, and that it was superfluous to question their intelligibility. Was it not to these laws that Descartes appealed, when seeking after the type of evidence? And yet, in order to establish the effective value of mathematics, this same Descartes regarded it as necessary to fall back upon divine immutability and truth. On the other hand, the entire empiric school calls in question the certainty proper to mathematics. It may also be said that the distinction between logic and mathematics is a fact of ordinary life ; judging by the mathematical inaptitude of certain dialecticians who, in other matters, are exceedingly subtle, and vice versa, there 
would appear to be two ways of reasoning, quite distinct from each other. These considerations call upon us to examine the nature of mathematical certainty.

For one school of philosophers, mathematics is a mere application, a special development of general logic. So thought Leibnitz. If this be the case, the difference between the mathematical and the logical laws is not an essential one: the latter are simply more general than the former; there is nothing in mathematics that cannot be reduced to logic. For other schools, on the contrary, in conformity with the doctrine of Kant, these two kinds of law are irreducible to each other; in the mathematical there is something more than in the logical relationship. Now, speaking generally, the speculations of mathematicians seem more favourable to the second theory than to the first.

What is there new in mathematics, when compared with logic? In a general way: intuition. Then what is it that characterizes mathematical intuition?

Logic, if we consider the matter closely, presupposes a given whole, a concept which it purposes to analyse;' in this 


\section{THE MATHEMATICAL LAWS}

concept, it admits elements set alongside of each other, and does not determine the bond that unites them. Mathematics, on the other hand, does an essentially synthetic work; it posits the relations which logic supposits, creates a link between the various parts of a multiplicity, proceeds from the simple to the compound, itself generates the compound instead of taking it as given. Thus, mathematical intuition is really something new, though in what way?

In conceptual logic, in so far as it is distinguished from really pure logic, the notion of the general actually embarrasses the understanding which is trying to arrive at perfect intelligibility. In mathematics, there is more than this. Fundamental definitions are not mere propositions. An infinite number of definitions are frequently condensed in a mathematical definition. For instance, in numeration, the unit is taken as the startingpoint, and the following definitions are formed : $2=I+I ; 3=2+I ; 4=3+I$, etc., or, in a general way, $a+2=(a+\mathrm{I})+\mathrm{I} ; a+$ $3=(a+2)+\mathrm{I} ; \quad a+4=(a+3)+\mathrm{I}$. After thus forming the definitions of the first few numbers, we add: etc. What is 
this etc. but the idea of an endless number of definitions, analogous to those we have created ? Now, the arithmetician reduces this infinity to the following formula: $a+b=$ $a+(b-\mathrm{I})+\mathrm{I}$, a definition which in itself contains an infinite number of definitions. Such a concept is more than a novelty, in relation to the purely logical concept: it is already a deviation from perfect intelligibility.

It is the same with demonstrations. Mathematics frequently calls for a mode of reasoning different from logical deduction, and which consists in generalizing, with demonstrative force, the result of a particular demonstration. This we see in the theory of addition, on which the whole of mathematics is based. Suppose we have to demonstrate that $a+I$ $=\mathrm{I}+a$. First we make $a=\mathrm{I}$, then we have $I+I=I+I$, by identity. Then we adopt a roundabout method, and say: suppose $(a-\mathrm{I})+\mathrm{I}=\mathrm{I}+(a-\mathrm{I})$. If this supposition is granted, adding $I$ to each of the two members, we have $(a-I)+I+I$ $=\mathrm{I}+(a-\mathrm{I})+\mathrm{I}$, which, on crossing out the terms that cancel each other, gives $a+\mathrm{I}=$ $\mathrm{I}+a$. We have supposed that $(a-\mathrm{I})+\mathrm{I}$ $=\mathrm{I}+(a-\mathrm{I})$. But if we call $(a-\mathrm{I}): a$, 


\section{THE MATHEMATICAL LAWS}

we are brought back to the preceding problem. We may continue in this way until we come to the case in which $a=\mathrm{I}$. This mode of demonstration is called reasoning by recurrence. As we see, it is a demonstration that contains as large a number of demonstrations as we please, since $a$ may be supposed as large as we please. The same kind of reasoning takes place in a great number of cases, for instance, in demonstrating that the sum of several consecutive odd numbers from I upwards is equal to the square of their number. This reasoning is a kind of apodeictic induction. There is induction, for in this case demonstration deals first with the particular, and generalization comes only afterwards. And the induction is apodeictic, since it extends to all possible cases. Now, from the logical point of view : it is strange that a generalization can thus be conceived as necessary; and the reason we are here compelled to bring together these two words, which might almost be said to repel each other, lies not only in the fact that mathematics is not a simple development of logic, but that it does not even simply differ from it, as synthesis differs from analysis. 
Mathematical intelligibility actually implies some modification of logical intelligibility.

If this is so, what is the origin of the mathematical laws? If they were wholly known a priori, their intelligibility would be perfect. As it is, they imply elements that cannot be fathomed by thought. We are compelled to acknowledge them: we cannot say we find them clearly springing from the fundamental nature of the intellect. Nor can they be connected with knowledge d posteriori, for they deal only with limits. A limit cannot be understood empirically, since it is the purely ideal term towards which tends a quantity supposed to increase or decrease indefinitely. The mathematical laws presuppose a very complex elaboration. They are not known exclusively either a priori or a posteriori, but are a creation of the mind; and this creation is not an arbitrary one, but, owing to the mind's resources, takes place with reference to experience and in view of it. Sometimes the mind starts with intuitions which it freely creates; sometimes, by a process of elimination, it gathers up the axioms it regards as most suitable for producing a harmonious development, one that 
is both simple and fertile. Thus, mathematics is a voluntary and intelligent adaptation of thought to things, it represents the forms that will allow of qualitative diversity being surmounted, the moulds into which reality must enter in order to become as intelligible as possible.

Such is the nature, such the degree of intelligibility of the mathematical laws. What follows, as regards their objectivity? According to Descartes, mathematics is realized as such deep within the sensible world; it constitutes the very substance of material things. After Descartes, this point of view became more and more limited and disputed, and the positivism of Auguste Comte summed up the results of criticism by declaring that the higher is not reducible to the lower, and that, the more we would account for a loftier reality, the more we must introduce new laws which have a specificity of their own and cannot be reduced to the preceding ones.

The mathematical laws, considered in themselves, appear inapt for realization, since they imply infinite number; now, an actual infinite number is altogether incon- 
ceivable. Every system of mathematical realism splits on this rock.

But then, the idealist will say, what makes inconceivable the reality of infinite number, is that we insist on actualizing it as substance. If mind is the only reality and things but the projection and representations of its acts, the mathematical laws may be conceived as real, in so far as they form, within the mind itself, the groundwork of the world of representations. Our answer to the idealist will be that his system has no justification. In order that we may find, in mathematics, thought itself rendered objective, the laws of mathematics would have to be perfectly intelligible; now, the mind cannot assimilate them without a certain effort. Moreover, our mathematics represents a particular form of mathematics; others are possible, but the reason we keep to our own is solely because it is more simple or convenient for our comprehension of external phenomena. How will the idealist distinguish what is absolutely necessary from what might be different in the development of mathematics?

There exists, it would appear, a means of maintaining the absolute objectivity of mathe- 


\section{THE MATHEMATICAL LAWS}

matics, in spite of the difficulties which the intellect experiences in realizing the infinite; and that means consists in saying that the law of the real is actually the radical inconsistency or illogism and even the identity of the contradictories. But what would then be conceived as realized would be something different from mathematics as such, since the latter was instituted for the very purpose of removing, as far as possible, the contradictions offered by phenomena.

According to others, the substance of things eludes us, but the mathematical laws represent their forms and relations; these laws are the common element between ourselves and external reality. Such, for instance, was the doctrine of Ampère. This is a simple and clear, though artificial, conception ; for the form and the substance of things cannot thus be radically separated. When the form of a thing is perfectly known, it is no longer possible for us to say that we are altogether ignorant of its nature. The separation between matter and form is only a logical one, it cannot be a real separation. Not only, then, are the mathematical laws unreal, both in the substantial and in the idealistic sense, but they do 
not even express a form of things that is really separable from their matter. All the same, mathematics cannot be regarded as a mere convention, a simple sport of the mind. It is a fact that mathematics does apply to reality. How far and in what way cannot be determined à priori. All we are permitted to say is that, since man, apparently, is no anomaly in nature, that which satisfies his intellect must not be unrelated to the rest of things. We may therefore conjecture that there exists a correspondence between the mathematical laws and the laws of things; but it is the study of the particular concrete laws of nature that will teach us how far, in effect, the mathematical laws govern reality.

What, in short, is the meaning of mathematics as regards the necessity which may be ruling throughout the world? These laws are still closely bordering on absolute necessity; but they are also very far from things and from reality. And though they evidently have a closer connexion with being than the logical laws have, still, we cannot say that they introduce absolute necessity into being, for they actually admit of a strict deduction only through imperfectly intelligible axioms 


\section{THE MATHEMATICAL LAWS}

which the mind has combined with a view to this very deduction. How far does the necessity peculiar to them rule in things? This we shall learn by comparing the physical with the mathematical laws. We must now apply ourselves to investigating them. In the next chapter, we shall take up the mechanical laws and the idea of force. 


\section{THE MECHANICAL I,AWS}

UR present object is to examine critically the idea we have of the laws of nature, in the hope of extracting information as to the relation these laws bear to reality, and the position of the human individual in nature herself. It is our ultimate end to know whether, in the present state of the sciences, we may yet regard ourselves as possessed of any power to act freely, any reality as persons. Along these lines, we have examined the logical and mathematical laws, which, after all, are more than laws and express the most general relations, the conditions of all the rest. We have shown that the laws of real logic cannot actually be reduced exactly to the only principle most certainly known $a$ priori, namely $\overline{\mathrm{A}}$ is $\overline{\mathrm{A}}$, and that concept, judgment, syllogism, all imply a new element : the many as con- 


\section{THE MECHANICAL LAWS}

tained in the one, or again the relation of the explicit to the implicit. Mathematics also introduces new elements which the mind cannot thoroughly assimilate: it creates relations of adjustment; it diversifies the identical with the aid of intuition; more than that, in its generalizations, it cannot dispense with a mode of reasoning which may be called apodeictic induction. If both the mathematical and the logical laws do not proceed immediately from the nature of the mind, neither are they deduced from experience. Indeed, were this the case, they would have to coincide with parts or aspects of reality : now, this is not so. Neither the universals of logic nor the infinite number of mathematics are given to us. We cannot even conceive how they could be. Thus, logic and mathematics are solely derived neither from knowledge a priori, nor from knowledge a posteriori : they represent the work of the mind which, incited by things to exert itself, creates a mass of symbols in order to subject these things to necessity and thus make them capable of being assimilated by itself. The logical and the mathematical laws testify to the mind's need of conceiving things as being necessarily deter- 
NATURAL LAW IN SCIENCE AND PHILOSOPHY mined ; [but it cannot be known a priori how far reality conforms with these mind-imagined symbols: we must appeal to observation and analysis of the real if we would know whether mathematics, in effect, rules throughout the universe. All that can be admitted, previous to this experimental study, is that there is probably a certain analogy between our intellectual nature and the nature of things. Were it not so, man would be isolated in the universe. This, however, is but conjecture. A consideration of the concrete sciences will alone enable us to say what degree of reality we must attribute to logic and to mathematics.

The laws of reality given to us as approaching nearest to mathematical relations, are the mechanical laws. The essential and characteristic element of these laws is the notion of force. In order to understand the formation and the present state of this notion, we will now study its historical evolution.

In antiquity, and especially in the times of Plato and Aristotle, what seems, above all else, to strike the human mind, is the difference between motion and rest. This opposition is made the point of departure, and it is admitted that matter, in itself, is in a state 


\section{THE MECHANICAL LAWS}

lof rest. What has then to be explained is the transition from rest to motion. To solve the question, the production of motion in man is considered. Now, motion appears, in man, as resulting from the action of the mind on the body. Thus, above matter, there is assumed a separate force, resembling a soul more or less, and as such, suited for acting upon bodies. This view may readily be connected with the teleological conception, in virtue of which God rules and moves the totality of things; thus, it shows itself favourable to ethics and religion. On the other hand, it opposes the progress of science. How, in effect, are we to gauge and foresee the action of an immaterial force, called upon to exert itself from aesthetic and ethical reasons? As a matter of fact, the science of the real made little progress, so long as it regarded things from this point of view.

At the time of the Renaissance, a totally different conception grew up. Instead of contrasting motion with rest, Galileo looked upon them as analogous : matter is self-sufficient, both in motion and in rest. Of itself and apart from supernatural intervention, it continues indefinitely in a uniform, rectilinear motion ; 
of itself, it can pass neither from rest to motion nor from motion to rest: it is the principle of inertia. No doubt, if we wish to bring before the mind the first origin of motion, we must presuppose a first impulsion, a fillip, -chiquenaude, as Pascal called it;-but as regards its present state, which alone is the object of science, matter contains within itself the explanation both of its motion and of its rest. From this idea of inertia, it was at first thought possible to infer the abolition of force as a separate idea. Thus, Descartes thought he could explain all physical phenomena by the one law of the conservation of the quantity of motion, a corollary of the principle of inertia. Force, as such, is banished from his system. This philosophy might have been developed deductively, like mathematics, of which it formed the continuation; but there came a time when it was confronted with facts and then found to be inadequate. Newton, in order to account for the motions of the heavenly bodies, regarded it as necessary to re-establish the idea of force. He started with the principle of inertia, according to which a body retains its uniform, rectilinear motion for an indefinite period. The heavenly bodies, 


\section{THE MECHANICAL LAWS}

however, moved in a curvilinear, non-uniform fashion. To explain this modification of motion, we must admit that some external force acts upon the moving body. This reappearance of the idea of force, moreover, is not the restoration of the ancient conception. The ancients regarded force as dwelling in a higher, metaphysical form; it acts from above, after the fashion of a soul; it is God Himself, who, by His perfection, produces the motions of the heavenly bodies. Newton, on the other hand, attributed force to matter; an atom has not the power to modify its own motion, but it can modify the motion of other atoms. Thus, without leaving matter, we come to explain modifications in the speed and direction of motion. God is eliminated from the world, in so far, at least, as $\mathrm{He}$ is considered to be an artist who produces by separate acts every detail of His work.

Are we not, however, restoring the occult powers of the Schoolmen if we admit the existence of such a force? Newton, as we know by his own declarations, does not regard attraction as a metaphysical force, analogous to a soul's activity, To him, this 
is but an expression, a kind of metaphor, pointing to a phenomenal relationship. Force, as he interprets it, is none the less the cause of motion. Now, cause must be prior to effect. If, then, this is not an occult power, at least it is something metaphysical and invisible, which logically precedes phenomena. Mathematicians have taken it into account, and so we find them, nowadays, endeavouring to transform the relation between force and motion into a simple mutual dependence, a mere relation of solidarity. It is in this way that force is defined as the product of the mass into the velocity. Here, force and motion are two data related to each other, without there being any necessity to inquire whether, it is force that is the cause of motion, or motion that is the cause of force : just as, in geometry, we have the relation of diameter to circumference.

$\checkmark$ [Is force, as thus conceived, reduced to a purely mathematical notion, or does it contain some new element? Doubtless, abstract mechanics does not differ from mathematics and consists solely of substitutions of formulæ. But abstract mechanics does not suffice for the realization of the science of nature. This 


\section{THE MECHANICAL LAWS}

was clearly seen by Newton; he tried to find in experience the mathematical principles of his natural philosophy. Now, what is that element which cannot be found in mathematics and which only experience can give us? It is the measure of the action which bodies exercise upon one another.] In mathematics, consequences are analytically deduced from definitions; we start with the identical and then diversify it. But, in nature, we start with things foreign to one another, such as the sun and the planets, and set up a definite, constant dependence between these things. We are really dealing, then, with a mathematical connexion, though it can neither be affirmed nor known a priori. Thus, what there is new in the notion of force, is, in short, the idea of physical causality, or, in more precise terms, the idea of natural law, strictly so called. FForce is a uniform dependence, experimentally known, between things exterior to one another. Consequently it contains an extra-mathematical element.

But then, may it not be said that the affirmation of the natural laws results from a special necessity of the mind? Following on Kant, profound philosophers maintain, 
even nowadays, that the notion of law is the result of our mental make-up, and consists of a synthetic, a priori judgment. These philosophers justify their theory by setting forth how such an idea of causal law is necessary in order to think phenomena, i.e. to reduce them to unity within a consciousness. Phenomena, in themselves, are heterogeneous with regard to one another. The notion of law, by establishing universal and necessary relations between them, gives them the only unity of which a heterogeneous multiplicity admits. This theory, to our mind, is open to objections.

At the outset, is it clear that we have an irresistible need to think phenomena, to reduce them all to unity, to set up between ourselves and them, in an absolute sense, the metaphysical relationship of subject and object? No doubt we have need of unity; but it is difficult to prove that this need takes precedence of all others and governs the whole of our intellectual life. Indeed, the history of philosophy offers us not only minds that aim at an explanation of the uniform by the multiple and the changing, but also logicians enamoured of a reduction to unity. 


\section{THE MECHANICAL LAWS}

Now, if unity in the conception of being is not necessary, neither are the means of obtaining it.

But we may go farther. Even granting that we feel this absolute, imperious need to think things, is it certain that the categories of the understanding realize the end assigned to them, viz. the assimilation of things by the mind? It would appear as though this point had been too readily granted to the Kantian doctrine. Indeed, to think things is to understand their particular affinities and connexions, to see how they unify and group together of themselves. Kant's categories, however, leave things as they find them, exterior and alien to one another. They bring them together artificially, as stones are brought together in building a house. They reconcile nature-which unites beings according to their consanguinity or kinship -with art-which brings them together in accordance with its own ideas of fitness. Is a bundle of sensations a thought taking possession of things?

This is not all, and we may enquire whether the position adopted by Kant can be maintained as ultimate, or whether it must not 
of necessity be transcended in one direction or the other. The objection is frequently urged that, if Kant's categories are purely subjective, it is inexplicable that nature should conform to them. Stated thus, the objection is perhaps not well founded; for, in Kantianism, what we call nature is already the work of the mind, not perhaps of the individual thought, but of the universal human thought identical in each individual consciousness, and the individual mind only recognizes empirically and successively that which reason builds up and unifies à priori. But it would seem that a somewhat similar objection might be raised. Either the laws, we may say, that the mind brings forward, will find analogous matter, obedient to their action, in which case how shall we know that the notion of these laws comes from ourselves rather than from the observation of things, that they are known to us a priori rather than $a$ posteriori? Or else things will not conform to these laws, and in that case shall we claim that it is ourselves who are right and nature who is wrong? It is clear that, as soon as it is proved that facts do not fit in with the limits we wish to impose upon them, we shall 


\section{THE MECHANICAL LAWS}

make it our object to free ourselves of these limits and form conceptions more in accord with facts.

Thus, the mechanical laws are not an analytical succession of mathematical truths; neither do they rest on synthetic $\dot{a}$ priori judgments. Are they derived from experience? The ancients claimed to obtain from experience only the general and the probable, i.e. what happens in the ordinary way of

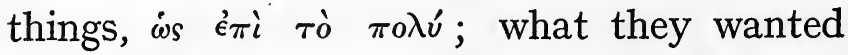
it to give them was universal and necessary rules, not laws. For the moderns, however, induction is a kind of magic word, in virtue of which, fact is transmuted into law. By so-called scientific induction, which evidently has scarcely anything in common with ancient induction, it is claimed that the universal can be deduced from the contingent, the necessary from the particular. Still, however productive and methodical modern induction may be, it will never succeed, without superseding experience, in bringing us to true laws. For instance, we cannot possibly, by experience, become acquainted with inertia and force; to do this, we should have had to be present at the 
NATURAL LAW IN SCIENCE AND PHILOSOPHY

creation. We never observe the exactly uniform and rectilinear motion of a moving body, removed from all extraneous influence, any more than the continuance in rest of a body that has received no impulsion. The duality of inertia and force, the action of multiple forces, and the composition of these forces, are abstractions that cannot be verified.

We may go even further and say that induction cannot even account for the most general characteristics of the mechanical laws. In fact, we observe only moments separate from one another, i.e. discontinuity, and yet our laws give us continuity. Secondly, these laws imply precision, whereas experience gives us only approximations. Afterwards, we assume, as fundamental, definite relations between such and such phenomena, whereas experience offers us an infinite number of relations between which there is neither priority nor separation. Finally, we attribute to our laws, fixity, as an essential characteristic. Now, in this we cannot say that we are judging the future by the past, for only to an insignificant extent do we know the past. It is most seriously alleged nowadays that species are not eternal, but 


\section{THE MECHANICAL LAWS}

have a history of their own. Why also should not laws, those types of the relations that exist between phenomena, be subject to change? The fixity we attribute to them is a characteristic that we add on to the data of experience, one that cannot be revealed to us from without.

Nevertheless, if the mechanical laws are known neither $\hat{a}$ priori nor $\hat{a}$ posteriori, in their distinctive form, it does not therefore follow that they are fictitious. $\sqrt{T h e}$ concept of law results from the effort we make to adapt things to the mind. Law represents the characteristic we must attribute to things in order that they may be expressed by the symbols at our disposal, the matter that physics must offer to mathematics, so that mathematics may unite with it. And the result proves that certain phenomena of nature comply with this requirement, the consequence being that the notion of mechanical law dominates the whole of scientific research, as a guiding idea, at all events.]

We have inquired into the nature of the mechanical laws; now we must examine their objectivity and signification, i.e. we must see how far we are justified in believing 
NATURAL LAW IN SCIENCE AND PHILOSOPHY

that things realize mechanism, and to what extent we are included in this mechanism. These questions will be dealt with in the next chapter. 


\section{V \\ THE MECHANICAL LAWS}

(Continued)

W ${ }^{\mathrm{E}}$ have seen that the mechanical laws are not a mere development and complication of mathematics; in reality, they imply a new element which cannot be reduced to mathematical intuition, viz. the solidarity of fact, the regular, constant dependence, empirically given and unknowable $a$ priori, between two different magnitudes.

We have shown that these laws are not purely experimental truths either. They result from the collaboration of mind and things; they are products of mental activity and apply to extraneous matter; they represent the effort which the mind makes to set up a coincidence between things and itself. Now we must inquire in what way the mechanical laws may be regarded as realized in nature.

The first step taken by the creators of 
scientific mechanism was to grant objective existence to those laws that enable us to explain things in so rigorous a fashion, and the first doctrine we find on this subject is dogmatism. According to this doctrine, the mechanical laws, as such, are inherent in things considered per se, apart from the mind at work upon them. Descartes teaches this metaphysical mechanism; he regards matter and motion, which are themselves capable of expression in terms of space, as representing the entire essence of things other than mind, and so the mechanical laws exist as such in nature ; more than this, they are the fundamental laws of the whole of $L$ nature.

Still, Cartesianism lends itself to serious objections. On what is it grounded? On the clearness peculiar to the idea of extension. But, given that clearness of the idea of extension, does it follow that extension is the essence of matter, as Descartes states it to be? Descartes himself succeeds only by having recourse to divine truth, as to some deus ex machina. But how are we to see in motion a thing that exists per se? Motion is not self-sufficient. Common sense 
tells us that it presupposes something that moves, and common sense is right. To establish a connexion between the different positions of which motion consists, we must have either a permanent subject such as matter, 'or a mind that contains the representations of these positions in one and the same consciousness. In a word, motion, of itself, does not involve the principle of unity, of which it stands in need in order to be real.

[Newton corrected Descartes' mechanism, though he remained dogmatic. When he says Hypotheses non fingo, he means that he is not satisfied, as Descartes is, with merely possible explanations, but that he aspires to find out the real, effective causes of things, the laws which God himself had in mind when he created and planned the universe. Newton introduces into nature that material subject which was lacking in Cartesian mechanism; he admits of bodies, endowed with forces, as a condition of motion, and thereby thinks he is securing, far better than Cartesianism did, the objectivity of the mechanical laws.] And so he acknowledges the existence of real motion, whereas, according to Descartes, there existed only relative motions. We must 
[carefully distinguish between Newtonianism as science and Newtonianism as metaphysics. Newtonianism as science is satisfied, as far, almost, as the human mind can be, with experimental or mathematical notions. But if we would convert this science into a knowledge of nature as existing per se, we must realize space, mechanical causality, force, atoms, and even attraction, or any other mode in which the cause of motion operates. And here arise the difficulties so well demonstrated by Berkeley, whose system, from the very outset, is a refutation of Newtonianism regarded as metaphysics.] If space, matter, atoms, mechanical causality, force, attraction and repulsion, says Berkeley, are looked upon as objective realities, we must first acknowledge that they are things which the human mind is incapable of knowing. It is only by a process of artificial abstraction that we detach them from the sensations of which we are conscious. They are never presented to us in themselves; they cannot be. Nor is this all. Not only are such things, for us, if they exist, as though they were not, but we cannot even conceive that they do exist, in themselves. In fact, these con- 


\section{THE MECHANICAL LAWS}

cepts, set up as things per se, become contradictory. Infinite and homogeneous space devoid of quality, the extended, indivisible atom, mechanical causality, wherein that which is powerless over itself, possesses power over something else, resulting in progression ad infinitum, the action of one crude body upon another, in whatever way this action is brought before the mind: all these symbols, taken as absolute realities, become unintelligible; nor need we be surprised if we remember that these concepts, when analysed, present elements with which thought cannot deal.

A third form of dogmatism is that professed by Leibnitz. According to him, there is everywhere at the same time both the mechanical and the metaphysical; the mechanical laws exist, though not separately and in themselves, as the mechanician conceives them. Their reality consists in the fact that they are well founded, i.e. supported by a reality distinct from themselves, but one that really exists and contains the requisita of mechanical action. This subject of mechanical phenomena is force, i.e. a metaphysical essence which, at bottom, offers a certain 65 E 
analogy with our souls. But this system also raises difficulties. [The mathematical formulæ of the mechanicians, from the time of Descartes right on to our own, have been so purged of all psychological or metaphysical content, that we no longer see any connexion' between force as metaphysics understands it and force as assumed by science. The latter is nothing but a measure of motions. It might with equal justice be conceived both as a consequence and as a condition of motion. The transition, then, from scientific to metaphysical force is lacking. Leibnitz's metaphysics is superimposed from without upon science strictly so called. True or false, it is no longer scientific mechanism that it sets up as a reality.

The mechanical laws, therefore, cannot be considered realized, as such, in the nature of things. The concepts of which they are constituted become unintelligible when converted into beings. Must they therefore be denied all genuine reality, and regarded, along with idealism, as nothing else than a symbolical expression, a projection of the laws of mind itself ?

Interpreted idealistically, the concepts of 66 


\section{THE MECHANICAL LAWS}

which the mechanical laws consist, avoid the contradictions that appear when they are interpreted realistically. Thus, space, a form of sensibility, is no longer contradictory, like space that exists per se. Mechanical causality, connecting representations with one another, no longer lends itself to the objections raised by this causality, conceived as connecting things. [But idealism is unable to stand its ground; and, the more closely it pursues the problem, the more it is compelled to recognize destructive elements within itself. As a principle, idealism consists in explaining the unconscious by the conscious, things by thought. But the history of philosophy shows us that, in order to explain the given, idealism is forced to appeal to the unconscious and allot this latter a place alongside of-or even above-the conscious. In the case of Kant, deep within the mind appears the synthetic judgment $a$ priori, which the intellect is compelled to accept as a sort of metaphysical fact, without really understanding it. Beneath the conscious self, Fichte places the absolute self, the activity of which precedes the intellect, and it is this activity which, when subjected to an inexplicable 
impact, explains the self as the not-self. In Schelling, the absolute becomes the identity of the self and the not-self ; in Hegel, it becomes the identity of the contradictories, that offence and stumbling-block to thought. Thus the self is more and more driven to leave itself and have recourse to some heterogeneous principle; idealism more and more abjures itself and approaches realism.

If then the mechanical laws do not exist objectively, neither are they mere projections of the conscious mind. They witness to the existence of something different from mind, and yet which must not be altogether separated from it. [We are foiled when we try to determine the substantial nature of things ; all the same, we cannot abolish them. All we can say is that, in things, there is a mode of being which suggests to our minds the invention of the mechanical laws. In reality, how do things act in nature? We can form a conjecture of this only by analogy, when we consider what takes place within ourselves. In short, consciousness is the only sense of being that we have at our disposal. Now, the phenomena which, in man, affect the mind in its most intimate union with the body, are the 


\section{THE MECHANICAL LAWS}

phenomena of habit, and it would really seem as though its effects bore a certain resemblance to mechanical causality. $\overline{\text { At }}$ first we have mental activity, in certain cases, at all events ; actions are related to thought, as their generating cause. By degrees, they fall away from thought, and jostle one another, as it were.' Thus, in certain cases and with certain men, words follow one another without being determined by thought; and so we find inertia and mechanical force in the persistence of our states of consciousness and in their mutual influence. This view may not follow from an induction based on the results of science, it is but a simple analogy; still, it constitutes the only way in which we can point to the reality of mechanical action. 7 To our mind, it is the degradation of true action, it is activity as represented by a link between its products, and thereby released and set free for new tasks. If such actions exist, the mechanical laws are the form we attribute to them, for the purpose of subjecting them to mathematical calculation. And so we see that the scientist can nowhere find the conditions of science accurately realized in phenomena. 
One final question : do the mechanical laws establish an absolute determinism?

There are few men, even amongst metaphysicians, who accept mechanical determinism as absolute. It is generally believed that man can produce movements in conformity with his volitions. In the very countries where determinism is professed by eminent philosophers, teachers and all who appeal to conscience and claim to regulate conduct, affirm the existence of free-will and of its power over things. We find this the case in England as well as in Germany. It is more difficult, however, to prove one's opinion, than to convince oneself of its correctness.]

How do we reason when we attempt to lay aside mechanical necessity? Common sense acknowledges that the soul is capable of producing movements; but that is simply appearance which will not bear investigation. The soul, it is said, is a force; but this is a much abused word. We passwithout saying what right we have to do sofrom the notion of moral or metaphysical force to that of mechanical force. If the soul is a force, in the sense in which it must be for 


\section{THE MECHANICAL LAWS}

imparting motion to a body by virtue of the principle of inertia, it must modify the quantity of force wherever it intervenes. But this in itself is strange and contrary to experience and induction, which show us that the quantity of force in nature is constant. Are we to say that the soul cancels a quantity of force exactly equal to that it produces? Such a conception would appear an entirely arbitrary one.

We find philosophers offering us a subtler explanation : that the action of the soul upon the body is real, although of a metaphysical, not a mechanical nature. Descartes acknowledges that the quantity of motion remains constant throughout nature, but that the soul may change the direction of the motion. The mechanical laws remain secure, since, according to Descartes, they do not determine direction, which latter must come from some other source. In spite of the objections of Leibnitz, which in all probability are not decisive, this expedient, interpreted in more or less complicated ways, has frequently been reproduced. Of recent years, M. Cournot, ascertaining that the amount of power necessary for the starting of a machine may 
be indefinitely diminished, recognizes a limit where this power would be nil. Then it would be replaced by a guiding force, belonging, for instance, to organisms or to thought. M. Boussinesq admitted that there were cases in which the initial state of a system does not wholly determine the course which the phenomenon must take. There would then be a greater or less number of bifurcations, making possible the intervention of a guiding force. Here the action attributed by Claude Bernard to life as a guiding idea, would find a place; life does not violate the mechanical laws, but it communicates to movements a direction they would not of themselves have taken.

This extremely seductive theory was upheld, as we see, by scientists of the first rank. It cannot be said, however, that it succeeded in becoming adopted. As regards passing to the limit, that is an expedient which offends the reason, and one which, in spite of appearances, does not seem to be authorized by mathematics. This latter declares A equal to B-in so far as their difference may be made smaller than any given quantity-only when A and $\mathrm{B}$ are both given as fixed, determinate 


\section{THE MECHANICAL LAWS}

quantities. A distinction is made between the true and the false use of the method of limits. Now, however small the force necessary for starting a machine may be conceived as being, this force is always required, it never becomes nil. The strange solutions of M. Boussinesq have been disputed by several mathematicians, and it would seem rash to regard the efficacy of freewill as depending upon speculations the proof of which is not perfectly evident.

An important distinction, however, appears to dominate the whole question. As long as, with Descartes and even Leibnitz, we confine ourselves to laying down laws of invariability or constancy regarding quantity in general, there is necessarily room for indetermination. The constant as a rule may always be secured in several ways. Newton, however, looked upon the mechanical laws as eliminating this element of indetermination. Indeed, Newton is not satisfied with an abstract law, he determines the quantity and direction of the motion which is to be realized in each case.] $\mathrm{He}$ envelops the law of conservation in a concrete law which indicates the mode of its 
application. If motion, then, is modified, it can only be by a formal derogation of law, by a miracle.

There is a particularly metaphysical way of escaping mechanical determinism, and that consists - whilst admitting this determinism for external phenomena-in breaking the bond which links to these phenomena the higher forms of existence. We are given a relation between organic movements and intellectual states. Now, if a determinate movement corresponds with each thought, and if movements are necessarily linked to one another, the consequence is that thoughts also are necessarily linked to one another. It is this dependence of thought as regards movement that certain philosophers endeavour to weaken or to destroy altogether. According to this view, Descartes acknowledged that when a passion is brought into being within us as the result of some external action, we are not condemned to become wedded to the thoughts called up by this passion. $\mathrm{He}$ maintained that we have the power to summon before the mind different thoughts, and to hold them there by means of attention. For instance, when the physical body impresses 


\section{THE MECHANICAL LAWS}

on us an impulse of anger, we can summon before the mind ideas of justice, moderation and duty, to replace ideas of vengeance. Thought, then, is not indissolubly connected with the physical organism. In one sense, Leibnitz goes much farther than Descartes; he breaks off all communication between body and soul, and maintains that the life of souls would remain the same even if all bodies were annihilated. On the other hand, he recognizes that there exists pre-established harmony and exact parallelism between bodies and minds. The mind, however, is not therefore made dependent on the body. It is the contrary to this that Leibnitz has in view, for he regards efficient causes as dependent on final causes. Kant simply abolishes all connexion between the moral subject and the world of motion; he regards the noumenon, which is entirely free from the fetters of mechanism, as having power to determine itself in an absolutely autonomous fashion.

These various theories are either ingenious or profound, still, hypothesis has a large share in them. In the first place, how is it known that the bond between 
the mechanical order and the higher orders is loose, or liable to be broken? Then, too, who is to guarantee that the orders of things, thus superimposed on the mechanical order, will not themselves also be determinisms, different, it may be, but equally inflexible? Still, even though this system were admitted, it would give us but little satisfaction, for it would leave quite out of our control the world of motion in space, i.e. the world in which we are living, after all, and on which it is primarily important that we should be able to act.

Mechanical conjunction, it must be recognized, is the most perfect form of determinism, for it represents the coincidence of experimental reality with mathematics. But what we have to discover is whether this determinism should be transferred from the explanation of the phenomena it governs to the very beings whose manifestations we are endeavouring to systematize. When we ask ourselves if the mode in which bodies act on one another compromises our freedom, we are misstating the question. Bodies do not act on one another. It is by a process of artificial construction and abstraction that we isolate 
a world of atoms and mechanical forces, and regard it as self-sufficient. In reality, this world is not self-sufficient. Not only cannot atoms and mechanical causality be conceived without a mind to think them, but mechanical movements themselves cannot be isolated from the physical and organic phenomena that exist in nature. Do we know whether the mechanical laws are the cause or the consequence of the other laws? If, by chance, they were the consequence, could we still affirm that they are rigorous and immutable? If there really are activities in nature, they are quite different from the so-called action of one body on another, which is nothing but a numerical relation. And as there is nothing to prove that the real support of so-called mechanical phenomena is itself mechanical and subject to determinism, there is no chain to be broken in order to enable a moral influence to permeate what is called the world of matter and motion. Bodies, in their reality, resemble us already, otherwise they are not for us. The distinction between laws or relations and phenomena or elements, copied from that between precepts and will, is a mental artifice for the reduction 


\section{NATURAL LAW IN SCIENCE AND PHILOSOPHY}

to ideas of the greatest possible amount of given reality. In being itself, this distinction disappears, and with it the determinism which implies it. 


\section{THE PHYSICAL LAWS}

${ }^{\complement} \mathrm{W}^{\mathrm{E}}$

have seen that experience intervenes, as an essential element, in the establishing of the mechanical laws. And yet these laws have a strictly mathematical form. I If they could exactly realize, without any sacrifice on either side, the synthesis of the rational and the experimental, they would express a really necessary determinism. The two elements, however, are not so much blended with, as set alongside of, each other: the mathematical element in the mechanical laws does not apply exactly to reality, and the experimental element in them remains unknown as regards its nature and cause. Anyhow, the harmony between mathematics and the experimental borders near enough on coincidence, in the mechanical laws, for these latter to be, in practice, the most perfect model we possess of necessary 
NATURAL LAW IN SCIENCE AND PHILOSOPHY

determination. We will now look into the nature of the physical laws, and see whether they are but one particular instance of mechanical determination, or possess an originality and meaning of their own.]

Man's first feeling was a consideration of the physical qualities which our senses reveal as inherent in bodies themselves; evidently, when thus regarded, physical phenomena cannot be reduced to mechanical phenomena. From this point of view, change implies a destruction and a production of substantial forms that is opposed to the homogeneity and continuity of strictly mechanical phenomena. This method of enquiry, however, is very unfavourable to science ; for things, when envisaged in this light, lend themselves but feebly to the application of mathematics. Consequently, the revolution that Descartes effected was useful in that it divested things of sensible qualities, which latter it attributed to the knowing subject. Descartes regarded clearness of ideas as indicative of their truth.] Now, sensible quality is not an object of clear ideas ; consequently, it cannot exist as it appears to us. On the other hand, extension and motion are objects of clear ideas. Besides, we 
have a natural tendency to refer our sensations to things in extension as being their cause. In virtue, then, of divine truth, this tendency must be a law unto us, and so we will affirm, $\grave{a}$ priori, that extension and motion must suffice to explain all the phenomena of nature. Physics is thus nothing more than a continuation of mechanics.

This theory could not be applied off-hand to facts ; and so, in the eighteenth century, special physical agents were superimposed on motion. Electricity was explained by two contrary fluids; light, heat, and magnetism were explained by distinct, separate fluids. Still, the Cartesian principle was never altogether abandoned: it continued to indicate the ideal of perfect science.

At the present time, we are once again tending to eliminate qualities and reduce the physical to the mechanical. This is proved by the mechanical theory of heat. In conformity with the Cartesian tradition, many scientists regard motion as an all-sufficient explanation of every physical phenomenon; as Tyndall said: heat is motion. Still, the most recent works of contemporary physicists 
show a certain mistrust of this theory. The reproach is made that it leads the scientist too much to reason deductively and to be too metaphysical.] When we say that heat is motion, are we not actually pronouncing on the very nature of heat? Recognizing this, Lippmann was careful to substitute for the expression "mechanical theory of heat," that of "thermodynamics," which does not forejudge the nature of heat; he also endeavoured to discover, not the essence of calorific phenomena, but simply their laws. We ought, then, to enquire whether, in accordance with the conclusions of modern science, there would appear to be in physics some element that cannot be reduced to mechanics, or whether, in the object of these two sciences. there is anything more than a difference in complexity and degree.

The essential character of a mechanical phenomenon is reversibility. In abstract or theoretical mechanics, a moving body which has just gone over the path A B must return exactly along the same positions, from $B$ to $A$, if the direction of the motion is changed. The conditions of abstract mechanics being sensibly realized in celestial 


\section{THE PHYSICAL LAWS}

mechanics, it is possible to say that if the direction in which a heavenly body moves were to be changed, this heavenly body would return exactly along the same points; it would describe, for instance, an identical ellipse. But in concrete mechanics, which is actually physics, since all power generates heat, reversibility is hindered or impeded by friction. Now, this difference is a general one : no physical phenomenon can be reproduced in identical fashion if its direction is changed. For instance, in the ordinary atmosphere, a pendulum going from $\mathrm{A}$ to $\mathrm{B}$, will have a certain resistance to overcome; to do this, it will have to produce power; in producing power, it will lose a portion of its energy. If, then, the direction of the motion is changed, this moving body will not return to the starting-point, since it has already lost energy on the outward track and will again lose energy on the return track. It may be set down as a rule without exception, that wherever there is expenditure of effort, there is both production of heat and irreparable loss of the original condition. This law introduces into physics an element quite different from those of mechanics. In 
mechanics, we are considering a force which always maintains the same nature and the same quality ; in physics, on the other hand, the quality is different: the expenditure of effort is higher in quality than heat, heat at $100^{\circ}$ is higher in quality than heat at $99^{\circ}$. Heat never wholly reconstitutes the expenditure of effort which gave birth to it; the amount of energy is continually decreasing, according to the principle of Clausius; the phenomena are irreversible, the ultimate result is always a falling off. What does all this mean, if not that physics cannot leave quality out of account, quality as thus understood, at all events? This was Cornu's maxim: in physics, he said, we have to consider not only the quantity of energy, but also its quality. The physical laws, then, cannot be reduced to the mechanical laws; a new element intervenes; quality. Of course, this is no longer scholastic quality; still, it is an element of differentiation and heterogeneity.

Let us now try to discover what it is, in reality, that corresponds to the physical laws, and how far we may regard them as existing objectively. 


\section{THE PHYSICAL LAWS}

When the mechanical theory of heat was established in science, philosophers thought they could turn it to considerable account. The law of the equivalence of effort-expenditure and heat was regarded as an instance of the general law governing the transformation of natural forces. They thought it would establish continuity between the most seemingly heterogeneous things. Indeed, if motion can be changed into heat, why should heat not be changed into vital force, and this latter into thought? All can be changed into all, and the dream of Heraclitus is realized; transmutation, which the alchemists sought after in metals alone, becomes the universal law of nature.

Renouvier, with considerable precision, showed the superficiality of this interpretation. The law in question, instead of proving the possibility of transformations, excludes them. Indeed, it is obtained only by eliminating the heterogeneous and considering the homogeneous side of things. The physicist lays aside the best part of the essence of physical phenomena, leaving it to the physiologist, the psychologist or the metaphysician; the laws he positsdeal 
only with the quantitative relations which. may be found on the surface of these phenomena. Instead of there being any transformation in physical production, as the scientist considers to be the case, there is a passing from the same to the same, a passing from one distribution of energy to another equivalent distribution.

[And yet, what is it that is conserved in nature if not a force capable of assuming all kinds of forms? Spencer regarded the reality of such a force as no less assured than the impossibility of becoming acquainted with its essence; to establish this dual characteristic of universal force, he invoked the conditions of our consciousness and mental constitution. The force of which we assert persistence is that Absolute Force we are obliged to postulate as the necessary correlative of the force we are conscious of. . . . In asserting it, we assert.an Unconditioned Reality, without beginning or end. Thus, quite unexpectedly, we come down once more to . . . the continued existence of an Unknowable as the necessary correlative of the Knowable (First Principles, §62, etc.). $]$ But then, as Dauriac stated in his remarkable work Des 


\section{THE PHYSICAL LAWS}

notions de matiere et de force dans les sciences de la nature, if that which is conserved is unknowable, how do we know that it persists? Either this transcendent principle has nothing in common with the forces with which science deals, and its so-called persistence explains nothing; or else it is the substance of the forces with which we are acquainted, and, in affirming its persistence, we are really affirming that transmutation of forces which there is nothing in science to warrant us in admitting.

According to Renouvier, that which is conserved is, strictly speaking, kinetic energy. But then, as we have seen, physicists nowadays are diffident of reducing phenomena to motion. There are even mathematicians who consider the two principles of thermodynamics as incompatible with mechanism. The energy, that is conserved, at the same time changes its nature, and its quality is continually diminishing. In reality, the principle of the conservation of energy is rather a mould or matrix of law than a single, determinate law. Whenever we consider a "closed-in" system, there is something conserved in it. This something will 
vary, according as the system is conceived as being formed of mechanical, of physical or of chemical forces.

There remains to be explained the concept of permanence. In this connexion, Helmholtz says that the question is not whether all the facts can really be reduced to constant causes, but rather that science, in so far as it insists on conceiving nature to be intelligible, must admit the possibility of such reduction, if only in order to acquire the unexceptionable certainty that our knowledge is limited (Mém. sur la conservation de la force, Introd.). The principle of the conservation of force, therefore, is, for science, a guiding idea, necessary in a way. But there is nothing to warrant that this law, as such, is inherent in the nature of things. In its profitable form, it is not known a priori, nor does it obtrude upon the mind. It was discovered by means of experiments and analyses, and consequently is essentially experimental and inductive. There is something artificial about it, like all induction, and it is difficult to conceive of it as being absolute. Indeed, given an ensemble of forces, either this system offers solutions of continuity, or it is shut in on all 


\section{THE PHYSICAL LAWS}

sides. If it is open to external influences, these may thwart the law, which, in that case, will be realized only in so far as the external influences are feeble and negligible. On the other hand, if the system is " closedin," the law of conservation is conceived only as co-existing with some cause of change. In order that energy may be conserved through the changes, then changes must take place. And if we would conceive things in their reality, we cannot separate conservation and change from each other, as we do the ingredients of a purely physical mixture. True, along with the laws of conservation we have laws of change, such as the principle of Clausius. These laws, however, are neither reducible to the law of conservation nor adequate for determining the phenomena with any degree of precision. The negative form of the principle of Clausius actually prevents this principle from generating a complete determination.

What, in short, as regards the problem of necessity, is the meaning of the physical laws? To answer this question, let us return to the distinction drawn between the laws of conservation and those of change. The for- 
mer are built up on the type of the mathematical laws; they are absolute, they set forth precise conditions, they are or they are not. They establish only a negative necessity, however. They are, in our opinion, barriers analogous to those formed by the logical laws, only closer and nearer to things : they leave the phenomena partially indeterminate. Indeed, we must guard against confusing determinism with necessity: necessity expresses the impossibility of a thing being different from what it is; determinism expresses the sum total of the conditions which make it necessary for the phenomenon to be stated just as it is, with all its modes of being. The law of conservation is one of abstract necessity, not a law of determinism; on the other hand, any law which, like the principle of Clausius, governs the distribution of force, is really a law of determinism, though it is and remains exclusively experimental. Such a law is no longer, like the law of conservation, a condition of intelligibility. There would be nothing shocking to the mind if bodies were to attract one another in inverse ratio to their distance, instead of doing this in inverse ratio to the square of the distance. 


\section{THE PHYSICAL LAWS}

The laws of determinism, purely experimental as they are, do not claim to be absolutely exact and rigid. Of themselves, they cannot denote a necessary concatenation. They would become laws of necessity only if they were reducible to the laws of conservation, and finally to the formula $A$ is $A$; or, at all events, if we had solid grounds for believing that they could, by right, be reduced thereto. This reduction, however, to unity, of the experimental and the logical, we find impossible. Either necessity without determinism or determinism without necessity; such is the dilemma confronting us.

Still, it will be urged, since our laws can be verified, it is at least natural and morally necessary to regard them as immutable. Such a conclusion, most certainly, supersedes experience. We do not know whether the physical laws are fundamental and primal or whether they are merely resultants. When questioned on this point, the physicists would either refuse to answer or would incline to the latter view. The very law of gravitation itself was not regarded by Newton as a primary law. $\mathrm{He}$ refused, however, to investigate its causes, alleging 
that he had no hypotheses to set up. We isolate these laws for convenience of study, and because experience obviously authorizes us to do so. But how are we to know that they form an absolute, that thus we have a self-sufficient side of nature, one that is not influenced by the rest? Are all these elements of reality, the qualities and forms of being, which have had to be eliminated in establishing physics as a science, really inactive, high above the measurable magnitudes isolated by science, like the gods of Epicurus, far above this world of ours? Does not thought, as well as the sense of reality, require that the different elements of the world should condition one another, for the world to be a unity? And if, in reality, the physical laws are not independent of the other laws that may lie concealed in nature, how can we affirm that they are immutable and inflexible? Possibly they are formed by evolution, as is said nowadays regarding animal species; possibly their fixity is a contingent state of things, not a necessity. It is not legitimate to take literally this determinism, which recognizes no cause for a physical phenomenon, other than some equally physical phenomenon, 


\section{THE PHYSICAL LAWS}

since such phenomena are but abstractions, and true action, if it does exist in nature, is something very much more complex.

To sum up, consideration of the physical laws, when compared with that of the purely mechanical laws, marks a certain progress in determinism, in the sense that modes of being which mechanics left indeterminate, are now explained according to laws. In becoming narrower, however, determinism becomes more complex and obscure, and less reducible to that analytical relationship which alone would appear to constitute necessity. 


\section{VII \\ THE CHEMICAL LAWS}

7 HE sciences with which we have hitherto dealt had all, though in differing degrees, an abstract object; they considered existing properties, but not beings of nature. Chemistry, on the other hand, takes account of concrete bodies existing in themselves. The result would seem to be that this science, from the philosophical point of view, has a wider range than the former ones, and that the determinism of the chemical laws penetrates more deeply into the essence of things. Let us now see if this is really so.

Chemistry is a comparatively recent science. As shown in the profound and learned work of Berthelot on Les Origines de l'Alchimie, the transformations of bodies were first explained by the spontaneous action, either of supernatural powers, or of

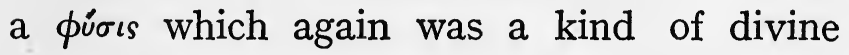
instinct, working apart from the mechanical 


\section{THE CHEMICAL LAWS}

laws. We find alchemy intervening between this more or less theological period and the present scientific period. According to the alchemists, man must be permitted, by every human and divine law, to utilize the forces of nature, and this is possible for him. The way to do it is to rely on nature herself : Natura a natura vincitur. Their theory is as follows. On the one hand, the corporeal elements are susceptible of transmutation; on the other, this transmutation admits of rotation, a circular process which returns to its starting-point. A serpent biting its tail is the symbol adopted by the alchemists. The former of these two principles may be confirmed by immediate experience; in a chemical transformation, we note a complete change of qualitative properties. But the alchemists, confining themselves to immediate observation, were mistaken as regards the simple and the compound. They looked upon the simple as that which is given, and the compound as that which is formed from the given. This identification of the given with the simple is an error identical to that which we find in the philosophy of Locke, for whom the simple was the given sensation, and the 
compound the idea resulting from it. The second principle of the alchemists also conforms with crude experience. Indeed, starting with metallic oxide, metal can be obtained; and, in the same way, if we heat the metal, the latter becomes an oxide once again.]

It was Lavoisier who, when tracing the real principles of chemistry, brought this science to its present condition (see Berthelot's Notice historique sur Lavoisier). In the first place, he established the fact that, in chemical transformations, not only does matter generally remain constant in quantity, but that even the special bodies on which the chemist operates remain unchanged in weight. Showing that the calcination of metals resulted from the union of the metal with a portion of the surrounding air, and not from a loss of phlogiston, he proved the metal to be the simple and the oxide the compound, thus changing the very foundations of the science. And in the second place, according to Lavoisier, special simple bodies, defined by their weight, must suffice to explain the formation of compounds. He offered a notable instance of this, explaining the composition of water by the combination of hydrogen 
and oxygen. Such mysterious substances as phlogiston were altogether eliminated. Thus, the so-called simple bodies set a limit on the decomposition and suffice for the reconstitution of the given bodies.] And so chemistry transfers to the species of bodies that permanence which mechanics attributed only to force considered generally.

The result is a most important difference between physics and chemistry. Is this irreducibility an absolute one? The different theories aim at lessening it as much as possible. According to the atomic theory, atoms, differing simply in weight, form and valence, by their various arrangements suffice to account for chemical phenomena. But these differences, especially that of valence, still constitute specific differences. This latter difference, which concerns the number of atoms susceptible of associating to form a molecule, cannot be reduced to physical or mechanical properties. For instance, in gravitation, a mechanical force, mass and distance alone enter into account. Moreover, the atomic theory of itself is powerless to reproduce the variety and complication of nature. Its complications are all to no pur- 
pose : the possibility of atoms exchanging semi-valences with one another, of atoms possessing four dimensions (that of azote, for instance), the mutual incommensurability of their weights. There is continually hovering above the atomic theory that dim mist of approximation which, according to Berthelot, casts a shadow over the whole system. For the present, we may conclude that chemistry is really distinct from physics, in so far as it admits of distinct species of bodies, the substratum of that profound chemical change which observation distinguishes from mere physical change.

What is the objective value of the chemical laws? If some day chemistry comes to be wholly reducible to physics, the reproach to which this latter lays itself open, that it is an abstract science when regarded as a science of being, will be brought against the former also. But the atomic theory claims, as interpreted by some philosophers who have adopted it, to explain, as regards its general form, the real constitution of matter. Let us examine if such a claim can be made for it.

Modern atomists take for their starting-point Newton's principle : "By effects to come to know 98 


\section{THE CHEMICAL LAWS}

causes," and, basing their conclusions on experience and induction, they think they can proceed from phenomena to being. But then, the atomic theory would first have to be precise and homogeneous for it to be capable of being regarded as a doctrine of being itself. Now, the difficulties we have mentioned above, especially as regards valence, show that the very idea of atom has not been definitely established. Stallo, the author of a learned work on La matière et la physique moderne, shows that chemists cannot guarantee the homogeneity, hardness and inertia of the atom, though these are all essential elements in its definition. Chemists also tell us of an energy of position, distinct from kinetic energy, and the reality of which it is no easy matter to reconcile with the principles of atomism. The truth would appear to be that this theory has been of great service, that it is valuable as a symbolic representation and doubtless the best we possess, but that it has no claim to determine metaphysically the nature of things.

We may go further and say: even were there a more complete coincidence between facts and theory, we should still have no right 
to regard atomism as a theory of being. Indeed, the principle $a b$ effectibus ad causas never offers anything but a subjective explanation. The atom cannot be known by the senses : it is conceived of only by the aid of hypothetical reasoning. Now, such reasoning never attains to anything more than possibility, the sufficient, or apparently sufficient condition, given the facts at our disposal; it never reaches the necessary condition. Speaking of the objections to which the atomic theory may give rise, M. Friedel alleges that no physicist is as yet disposed to throw overboard the undulatory theory of light, on account of the grave difficulties, and even contradictions, which the conception of luminous ether offers. In the same way, he said, it is better to continue to use a theory which has enabled a vast number of facts to be grouped together, and which daily leads to the discovery of fresh ones. Such language is a tolerably clear indication that there is no intention, in the name of science, of setting up atomism as absolute truth.

Metaphysics, however, supports this theory, and claims to bring it the aid which science neither can nor will afford. In a general 


\section{THE CHEMICAL LAWS}

way, it is maintained that the atom is the element which unites reality and intelligibility in the highest possible degree. The atom, it is said, is real, for it is determinate, both in bulk, in magnitude and in shape; it is intelligible, for it is defined by the qualities we conceive most clearly: the geometrical qualities. Moreover, we need only conceive of the sensible qualities as connected with the properties of atoms, to explain, by means of these latter, the changes which seem to be effected in the nature of bodies. The atom, then, is both intelligible and a principle of intelligibility.

But these affirmations are open to criticism. First of all, we cannot explain the endless variety of things by means of the atom, without making of this latter a more or less extra-scientific notion. Thus, some scientists consider that the extended atom cannot be reconciled with the centrifugal force implied in the relations between atoms at short distances from one another; they reduce the atom to nothing more than a centre of force, devoid of extension and yet situated in space. Such was the hypothesis of Boscovich, revived by scientists like Ampère, 
Cauchy and Carnot (see Pillon's fine article on "l'Evolution historique de l'atomisme," in the Annee philosophique for I89I). On the other hand, in order to explain by the combination of atoms the phenomena of sensation and thought, certain metaphysicians endow the atom with psychic as well as with mechanical and physical properties. For instance, in the system of Epicurus, we find the clinamen, which, after all, is no more than an ébauche of free-will. In modern times, atomism entered on a new phase with Locke, as Pillon has shown in the above-mentioned article. God is omnipotent, says Locke, and therefore, without contradicting himself, he can endow the atom with both extension and thought. Following the lead that Locke gave to atomism, Maupertuis attributes to the atom a rudiment of sensibility and thought, apart from physical qualities. This point of view is also seen in a scientist like Haeckel, who regards the atom as animated, and looks upon the elective affinity of bodies as a manifestation of tendencies, sensations and volitions.

And so, by varying at will our idea of the atom, we have come to regard it as explain- 
ing everything; though at the same time we have made this explanation anything but convincing. TSpeaking generally, atomism can give a reason for everything, provided it endow the atom with the very thing that has to be explained.] Now, this way of developing atomism contradicts its principle, which is essentially one of economy, in more precise terms, the idea of explaining the higher by the lower, the appearance of finality by mechanism, mind by matter.

To return to atomism strictly so called, i.e. to geometrical atomism, are we certain that it reconciles intelligibility with reality?

The starting-point of modern atomism is the Newtonian distinction between space and bodies. Space is nothing else than a vacuum, and a vacuum is unthinkable. Bodies are magnitudes, but they cannot be measured absolutely, for we have no absolute unit of measurement and we cannot compare the atorn with the point in mathematics, without falling into the insuperable difficulties of the infinite. Extension is never anything but a relation. It is the same with weight : weight is a relation depending on terrestrial attraction. In a general way, we only make use of 
experience in order to determine the size or the mass of atoms. Now, experience can offer us no more than the relative. Thus, doubtless, the notion of the atom is clear and evident, so long as we are dealing with the abstract, but when we wish to determine the atom with reference to its location in space, its form, extension or weight, thought finds itself faced with a mere relationship, proceeding from an insuperable indetermination. After all, the atomic theory offers us nothing else than the imaginative scheme of the notion of law, just as a curve represents to the eye the variations in temperature or the increase or diminution of the population. By definition, a natural law is a constant relation between two definite, immutable terms ; a couple of atoms whose mutual action depends solely on their distance well represents this relation. Adequately determined, the atom supplies schemes that correspond to the physical and chemical laws, which are conceived after the model of the mechanical laws. This representation is a very natural and convenient one, though relative to our imagination, for which it has been constructed. A metaphor is not a being. 


\section{THE CHEMICAL LAWS}

What, in short, is the meaning of the principles of chemistry as regards determinism? It is noteworthy that, in antiquity, atomism was a doctrine of atheism, or, at all events, of the non-intervention of the gods; whereas, in the case of the moderns, it does not, as a rule, exclude religious beliefs. Newton closely connects the idea of God with the nature of space and of the mechanical laws of the universe. Boscovich is a spiritualist; he subordinates the existence of the world, which he regards as contingent, to the will or arbitrament of an infinite power. This difference would appear to result from the notion that has been formed of inertia. Indeed, the atomists of old admitted that matter possesses within itself a principle of motion : therefore they had no need of the workings of a God. The moderns, on the other hand, consider mass and motion separately, and look upon them as independent of each other. Therefore their union may seem to require the intervention of a supernatural power. A God is needed to give a start, an impetus. In spite of numerous examples of reconciliation between atomism and religious beliefs, it seems correct to say that atomism, 
speaking generally, remains hostile to ideas of providence and freedom. Indeed, its tendency is to explain the more by the less; and so it endows atoms with the fewest possible qualities, those, too, that are farthest removed from mind; and in this philosophy, even when it is thought that God must be appealed to for an explanation of the existence of atoms, divine action is reduced to a minimum ; it is admitted only in so far as it cannot be dispensed with.

Still, let us consider not atomism but simply the general idea of the chemical laws, to wit, the principle of the permanence of the weight of bodies. Physics and chemistry show us everything seemingly permanent in nature, mass and energy alike. What is this permanence? We are inclined to think that everything we attribute to permanence we withdraw from contingence and freedom. But this may be no more than a prejudice, the origin of which would seem to date back to antiquity. The ancients regarded fixity, immutability, as the ideal. Epicurus considers the gods as being eternally unoccupied, for work is a change of state, it implies fatigue. But these ideas are not so 


\section{THE CHEMICAL LAWS}

current amongst the moderns as they were amongst the ancients. Many of us look upon motion as superior to repose. For æsthetic and moral reasons, perhaps, as well as scientific, our conception of being and of the ideal has changed; nowadays, it admits of-even if it does not exact-progress, improvement, flexibility. And therefore immutability is no longer the mark of the absolute, but rather of the relative. Mass and energy are immutable, therefore they are only phenomena. We conceive of permanence either as a state or as a limit, no longer as a necessity inherent in being.

Moreover, we may note that determinism becomes obscure the more it contracts. Mechanics has actually had to substitute for mathematical intuition a relation of simple phenomenal causality, incapable of being reduced to this intuition. Physics has complicated this relation by introducing a notion of quality, that of energy. Chemistry adds the idea of special bodies, relatively permanent in nature. Progress takes place from the homogeneous to the heterogeneous, consequently from the intelligible to the obscure. 
NATURAL LAW IN SCIENCE AND PHILOSOPHY

On the other hand, every one admits that physico-chemical determinism may act upon mechanical determinism without the former being reducible to the latter. $A$ priori, then, there is nothing to prevent physicochemical determinism, in its turn, from admitting of the intervention of some superior determinism, biological determinism, for instance, if it were to happen that it could not be reduced to physico-chemical determinism. 


\section{VIII}

\section{THE BIOLOGICAL LAWS}

$\mathrm{N}$ his Nouveaux Eléments de Physiologie 1 humaine, M. Beaunis reduces the biological laws to two principles: first, the correlation of physical with vital movements; second, the evolution of living beings. Conformably with this division, we will now study the relations between physiology and physics; and, in the next chapter, take up the relations of species with one another, and the question of evolution.

Are the general laws of life reducible to the physico-chemical laws? Let us first examine the matter from the historical point of view.

Descartes declared that every science, the science of life as well as those of matter, must be reducible to mechanics; he himself made attempts in physiology, along 
these lines. Modern science, however, did not originate immediately in this synthetic view. M. Gley ${ }^{1}$ dates the beginnings of modern physiology from the English doctor, Glisson. Now, the latter bases this science on the notion of irritability, which he regards not as reducible to mechanism, but as a special property, peculiar to living beings; a lower form of the very faculties that constitute the human mind: appetition and perception. In a second period, comprising Haller and Bichat, vital phenomena are clearly distinguished from physical ones, but more attention is bestowed on their analysis and division into categories than on the inquiry as to whether or not they have any special basis. This analytical period offers a striking analogy with the psychological period mainly represented by Jouffroy. A third period begins with Broussais: its main representative is Claude Bernard. We work up from phenomena to their principles; we ascend from vital faculties to irritability, doing away, however, with the idea of mysterious powers and attempting

1 Dictionnaire encyclopédique des sciences médicales, article on "Irritabilité." 
to reduce this very irritability to mechanism, in accordance with the Cartesian principle. Thus we introduce a strict determinism into physiology. In examining what this reduction consists of essentially, we will base our argument on the Eléments de Physiologie of M. Beaunis and on Dr. Gley's remarkable article just mentioned.

Present-day science teaches that in the living being: $I$, there is no spontaneity; 2 , reaction is equal to action. Protoplasm is the common element of all tissues. It enters into motion only when subjected to some particular mechanical, physical or chemical excitant. What is true of the element must be true of the compounds. Again, in living beings and in the organic world alike, there is equality between action and reaction. Of this we become more and more conscious, ", as we consider, with increasing precision, the amount of material supplied and of effort and heat expended, in the case of living beings. The law of the mechanical-equivalent of heat applies to living beings. The reason they appear to expend more force than they receive is that they have reserve forces of tension which are suddenly released beneath 
the influence of the exciting agent. Strictly speaking, they are machines capable of storing force. No doubt every kind of tissue appears to have special irritability, but this difference in manifestation results from the complexity of the tissues and the different way in which their cells are arranged. The final reason for irritability lies in the nature of the substances which compose protoplasm; these admit of a great variety of combinations: carbon, for instance, which is tetravalent. Impermanence of protoplasmic substance is the essential condition of irritability. And the progress of organization is nothing but the increase of this very impermanence. It would thus appear that the reduction of physiology to physico-chemistry, if not actually effected in detail, is at all events certain in principle and assured in the future.

Still, if we consider the usual language of the physiologists who are labouring to justify this induction, it would seem that results have not yet come up to intentions. Claude Bernard wrote : "It is clear that this evolutive property of the egg, which will produce a mammifer, a bird or a fish, belongs neither 


\section{THE BIOLOGICAL LAWS}

to physics nor to chemistry." 1 And M. Beaunis said: "There is always a certain constancy in the outer form of living beings. Each organism is built up according to a morphological type, from which, in the course of its existence, it can only deviate within restricted limits." 2 M. Gley said : "Not only does the being or the tissue react, when affected by an excitation in its environment, but it appropriates its elements to this reaction; for, under penalty of deposition, perhaps of death, it is compelled to adapt its physical nature and chemical constitution to this change in the conditions of existence." 3 Do not such words as these seem to indicate that the living element tends to subsist in its individuality and employs the appropriate means of realizing this end? Still, it is quite possible that these scientists merely continue, as a matter of habit, to use ordinary language, just as the astronomer speaks of the sun's motion round the earth, or of its rising and setting. Let us consider things in themselves.

1 Claude Bernard, La science expérimentale, p. 210; Gley, art. "Irritabilité," p. 487.

2 Beaunis, Traité de Physiologie, 2nd ed., I7.

3 Gley, article on "Irritabilité," p. 489. 
It cannot be doubted but that life, to Claude Bernard, is really a "controlling idea," distinct from mechanism. He regards this theory as playing too important a rôle for it to be looked upon as only a metaphor, a way of speaking. Claude Bernard attributes to living beings, in their own right, the following characteristics: organization, generation, evolution, nutrition, decay, sickness and death. These phenomena he regards as inexplicable apart from life as a special principle. "Vital force," he says, "controls phenomena which it does not produce; physical agents produce phenomena which they do not control." 1 M. Marey writes : "For myself, I am not acquainted with the phenomena of life; I acknowledge only two kinds of manifestations of life : those intelligible to us, which are all of a physical or chemical order; and those that are unintelligible." 2 There are gaps, then, in mechanism; certain aspects of the living being, in the present state of science, appear to be unintelligible, i.e. irreducible to physico-

1 Claude Bernard, Leģon sur les phénomènes de la vie, i. 5 I.

2 Marey, Du mouvement dans les fonctions de la vie, 3rd lesson.-Gley, article on "Irritabilité," p. 486. 
chemical forces. What is it that shrinks from mechanical explanation in this way? It would seem to be a principle of finality, inherent, in spite of everything, in the most elementary vital phenomenon. The living being is reduced to protoplasm, whose function it is to react under the influence of external activities. In it, we say, spontaneity is nil, reaction is equal to action. But, it may be remarked, this reaction is not any kind of a reaction; it is incompletely characterized when defined from the sole standpoint of quantity, for it possesses the unexpected property of favouring not only the conservation, but also the development and propagation of the very individual that reacts. The exercise of irritability is expressed by losses ; now, organic matter reacts exactly in such a way as to make good these losses. Besides, it reacts so as to adapt itself to environment, to make life possible for itself in the various conditions in which it happens to be placed. In short, by a process of reproduction, it en- $\checkmark$ sures the perpetuity of the form it represents. It has frequently been said that life is essentially a vicious circle. The organ makes the function possible, and the function is the 
condition of the organ ; muscular contraction accelerates the circulation of the blood, and the circulation of the blood keeps up muscular contraction. In every important physiological phenomenon we find the vicious circle. In the living being, then, there would appear to be an internal finality. The living being, regarded as an individual, makes use of that which is around it to ensure its own subsistence. The reflex action that characterizes it offers two aspects: the one, which concerns physics and chemistry; the other, which has no analogy in the objects of these sciences.

There is one phenomenon which emphasizes this difference, and that is death. Death finds no explanation in mechanism: this was why Descartes dreamt of an indefinite development of human life; and those who maintained the theory of mechanism, for the most part, saw no radical impossibility in the immortality of the living being, reparation always exactly making up for the wearing away of tissue. M. Sabatier ${ }^{1}$ thinks that death is intimately connected with the

1 Essai sur la vie et la mort; 1892. 
use made, by the living being, of the cells of which it consists. At first, the living being had no other function than to continue to live. It was then very slightly differentiated. To render higher faculties possible, the cells have become differentiated and have acquired complicated structures. Loss of their potential immortality has been the consequence of this progress. At the present time, only the reproductive cells, which are relatively simple, retain comparative immortality, which is realized either immediately by scissiparity and gemmation ; or indirectly, by way of a plasmocaryogamic rejuvenation. The cause of death is dual. There is an internal cause, the aspiration to rise, to supersede life pure and simple in order to attain to knowledge and feeling: it was to satisfy this tendency that differentiation of tissues, the origin of their mortality, came about. There is also an external cause : the outer appeals beneath the influence of which the tendency is realized. The biblical account of how man loses immortality when he tastes the fruit of the tree of knowledge is, according to M. Sabatier, an exact symbol of the cause of death. Thus, when 
Pascal proclaimed that man is greater than nature because he knows that he dies, he was propounding a view which was not only metaphysical and moral, it was also scientific. The best men in a nation, said Renan, are those it crucifies. Martyrdom is the ransom of superiority. Death, then, is a witness to the effort made by the living being to rise above the environment in which he was born. Defeat is the mark of his greatness. All these considerations are both poetical and religious; and yet scientists, as well as the rest of mankind, are influenced by them." Then what is the relation between vital faculties and physico-chemical properties?

Can physiology be established, like chemistry, by eliminating purely and simply everything that does not appear susceptible of strictly scientific determinations? The chemist does not deny that there are sensible qualities, but he relegates them either to physiology or to metaphysics: he finds a relatively isolable object of science in the relations of molecular composition. In the same way, it may be alleged, when studying living beings, we distinguish, on the one 
hand, physico-chemical phenomena, and, on the other, an indescribable something which resembles finality: this latter element is relegated to psychology or metaphysics, or even to the unknowable; and physiology is established as a science, no account being taken of any but physico-chemical manifestations.

But is the separation, that was possible in chemistry, possible also in physiology? It would appear that this triumphant adaptation to the conditions of existence, this choice of means suited to ensure the persistence of the individual, this tendency to expand and rise that we have remarked, here form one with the object of science. The amœba, one of the simplest of beings, a homogeneous -and almost diffluent-substance, has these properties to a striking extent. If an amcba is plunged into a liquid, and it there encounters a foreign body on which it is able to feed, for instance, a particle of vegetation, we find its prolongations gradually extend around the grain, finally surrounding it completely and uniting with it, so that the latter forms one with its own bulk. Then follows a certain period during which digestion takes place. In the 
end, the useless portion of the foreign body is expelled, by a process the inverse of that by which it entered. This is not a mere chemical combination. Still, the amœba is a very elementary organism. It is not given to us to see the physico-chemical properties become vital properties by a process of simple particularization.

Such is the present state of our knowledge ; but it may seem as though the future were destined to realize this exact reduction, which is, so far, only an ideal. M. Sabatier, in the above-mentioned work, makes a strong effort to compare living substance with inorganic substances. He regards the essential property of protoplasm, by which it effects selfrestoration and communicates life, as being, after all, only a "baiting" kind of power. Now, we have instances of similar powers in inorganic matter. Such is the phenomenon of superfusion. Phosphorus melts at $40^{\circ}$ Centigrade; its temperature may gradually be diminished below $40^{\circ}$ without any cessation of its liquid state; but if a solid piece of phosphorus is introduced, the entire mass immediately becomes solidified. We find that a similar thing happens in the case of syn- 


\section{THE BIOLOGICAL LAWS}

chronous oscillations. If any one string of a violin is set vibrating and a second violin happens to be near the first, the corresponding string of the second instrument vibrates in unison. In like fashion, the explosion of a dynamite cartridge provokes the explosion of other cartridges in the neighbourhood. But these are only comparisons, since living matter must always be presented as such. And, in a general way, the intercalation of intermediaries could not be mistaken for proof of identity or of causality. Ascending by shorter stages is by no means a cessation of ascending.

In reality, there is but one possible demonstration of this reduction: the artificial production of an organic substance from inorganic matter and physico-chemical forces; but such a process is still far from being realized. Pasteur declared most emphatically that the living never springs from anything but the living. No doubt this refers to the present state of things. It must be considered, however, that in itself the proof in question is very difficult to realize; for we must be very certain that the materials from which we think we see life 
emerging are really inorganic. If matter, says M. Sabatier, produces life, then it is not matter, pure and simple. Life is everywhere, he thinks, in so-called inanimate matter as well as in living matter.

Still, from the philosophical point of view, can we adhere to these assertions ? The mind pursues the reduction to the universal of everything that appears as new and heterogeneous. Now, finality is heterogeneous to mechanism. However indispensable it seem, may not the finalistic point of view be relative to our intellectual constitution? This was the opinion of Kant, and it is a very tenable one. We must remark, however, along with Kant himself, that the extension of mechanism to everything that is, is not philosophically imperative. How is this extension brought about? We note the extreme fertility of mechanism which, by degrees, explains the phenomena for which, moreover, it was thought right to infer occult qualities, and we are inclined to believe that, in time, everything will have a kind of mechanical appearance. But, admitting that everything must some day be reducible to unity, what is there to prove that absolute science 


\section{THE BIOLOGICAL LAWS}

will be only an extension of mechanical science, and not a superior science, into which mechanism itself enters, as a species into a genus? At bottom, it is here implied that all is in all, that a given phenomenon contains all the laws of nature, and that, if there exists a science whose form is henceforth perfect, that science must contain all the rest in embryo. Mechanics, or the science of motion, possesses this relatively perfect form; therefore, it is hoped that mechanics will succeed in explaining everything. Our mechanics, however, is not absolutely intelligible, as it is believed to be ; indeed, applied mechanics must be considered apart from rational mechanics. Now, experience is indispensable in applied mechanics, and, since all experience is limited, the results it gives us are nothing but approximations. In the final analysis, our reason for believing in universal mechanism is, as Descartes saw, our confidence in the truth of clear ideas and in their connexion with reality. We claim that the mind, freed from the influence of the senses, is the standard by which we measure things; 7 we also consider that, if everything is motion, we have power over 
everything, since we can produce motion. But Descartes clearly saw also that, if we would prove for ourselves the legitimacy of this point of view, we must fall back on the idea of a powerful, benevolent God, who has proportioned things to our means of knowledge and action.

And so, the more we wish to rise from phenomenon to being, the more we are compelled to find room for feeling: it has a part in the affirmation of universal mechanism. But feeling also supplies us with data opposed to mechanism. For, though consciousness may not have arrived at physicochemical forces, it actually does lay hold upon life. We are conscious of living; a purely illusory consciousness, if mechanism is truth; for, to mechanism, the elements alone exist and their rapprochement is nothing. Now, life shows forth as the effective synthesis of an extremely rich multiplicity. To believe the testimony of consciousness on this point is to doubt the absolute value of mechanism.

But, it will be urged, how are we to look upon the relation between life and physicochemical phenomena? Either life will break 


\section{THE BIOLOGICAL LAWS}

the chain of movements, or it will find itself banished to intermundane spaces. $\overline{\mathrm{We}}$ seem to have escaped from Cartesian mechanism only to fall back upon miracles or a state of pre-established harmony.] It may be that this difficulty in our way of representing life and its relation to mechanism arises from the fact that the question is imperfectly stated. Life and mechanism are both regarded as being things per se. Between life and mechanism we endeavour to find some relation which is still mechanical. The two, however, have no existence separate from each other; they are artificial entities; and the struggle which seems to result from their opposition is due to the fact that the human mind is incapable of grasping reality in its unity.

To sum up, the laws of physiology appear to be irreducible. Physiological determinism, considered in itself, differs from physico-chemical determinism, just as the latter differed from a purely mechanical determinism. It is stricter, for it governs phenomena which the physicochemical laws left indeterminate. It is based, however, on a more complex and obscure idea of law : the relation of one fact not only 


\section{NATURAL LAW IN SCIENCE AND PHILOSOPHY}

to another, but to a fact presented as an end, an object to be realized. Determinism, as it contracts, becomes more impenetrable, more irreducible to necessity. 
IX

\section{THE BIOLOGICAL LAWS}

\section{(Continued)}

$\mathrm{N}$ the last chapter, we saw that the reflex 1 act to which contemporary science endeavours to reduce all physiological phenomena is a sort of dual-faced phenomenon : on the one hand, it comes within the scope of physico-chemistry; on the other, presenting strictly the physiological aspect, it shows forth characteristics that are irreducible. Each order of science thus implies postulates proper to itself. We will now study, not the living being taken by itself, but rather the relations which living beings have with one another, that is to say, the laws which bind organic forms together. We will simply set forth an historical statement of the main phases through which zoology has passed, disentangling the philosophical ideas that have guided its development. 
Aristotle is the founder of natural history; and his scientific conceptions may be traced back to the general principles of his philosophy. Speaking generally, he made it his business to investigate the first causes of order in the world. Now, according to the Aristotelian doctrine, the world consists of two elements : matter, whose distinctive nature is a lawless mobility; and a principle which fixes and regulates this impermanent, capricious matter. As species present a striking permanence and harmony, they must depend on principles superior to matter. These principles are metaphysical entities, immutable types, perfect forms, acting on matter as final causes, as models to be realized, in so far as the nature of the elements permits.

From these principles result the gradations of living beings. There is not exactly amongst them unity of composition and a simple difference in degree; they rise in tiers, so to speak, one above the other, the upper ones possessing more qualities and greater perfection than the lower. The more implies the less, but it does so by adding to it. Thus, the lower orders of living beings possess nutritiveness; animals possess nutritiveness 
and sensibility ; man possesses nutritiveness, sensibility and intelligence. At the same time, however, nature, through the continuous matter at her disposal, multiplies the intermediate stages between these forms and proceeds from one to the other by scarcely perceptible transitions.

Are species fixed? Not altogether; ideal types, indeed, neither are nor can be exactly realized by matter; they represent models round which nature gravitates, which she tends to reach but never perfectly realizes. Fixity of species, then, is an altogether ideal immobility, permitting and even requiring a real and in a sense indefinite variability, whilst opposed to any being altogether overstepping the limits of the species to which it belongs.

In this doctrine, even teratological cases can be explained by natural causes. These are extreme dissimilarities, the result of excess or defect. They are connected with the dualism of end and of conditions, and with the capricious mobility of matter. Matter never fully realizes form ; at times it deviates considerably from it.

If this was the doctrine of Aristotle, was it 
owing to the fact that he had no idea of a mechanical explanation in zoology? To convince ourselves that this was not so, we need only quote a few lines from the Physics:

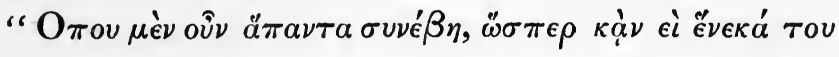

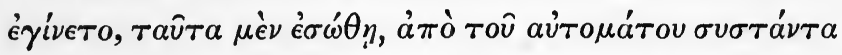

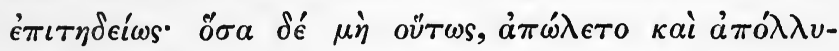

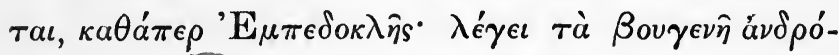

$\checkmark \pi \rho \omega \rho \alpha . " 1$ [Here we have the idea of natural selection in all its preciseness. The reason Aristotle rejects it is that, in nature, he considers order to be the rule, not the exception, and that chance may well account for a few isolated cases of fitness and harmony, though not of a general, constant order.

Thus we see that Aristotle regarded the zoological laws as being of an essentially teleological character.

[For Descartes, science, in its ensemble,

1 Where everything came about in such fashion that creation seems to have been controlled or guided by intention, in reality, there was nothing more than the survival of those beings which, by mere chance, were best adapted to survive : those that did not possess this adaptation were utterly destroyed and perish, as Empedocles says was the case with the human-faced beings that sprang from oxen.-Aristotle: Physics, viii, I98, b. 30. 


\section{THE BIOLOGICAL LAWS}

assumes an altogether different aspect. The logical point of view of systematization is substituted for the metaphysical one of explanation by generating causes. No longer does Descartes seek an explanation of the nature of things in æsthetic and moral ends. Not along these lines, he thinks, can a scientific explanation be found. God is infinite and he transcends us infinitely; his ways are inscrutable, and therefore it would be rash and fruitless to attempt to fathom them. What is both possible and profitable, is the explanation of phenomena by the essences immanent in them, the accounting for nature by exclusively natural principles. Hence, nature appears as a system, a structure whose unity and explanation lie in the conjunction of the various parts. Moreover, this idea of logical systematization is determined in two different ways, as we see in the naturalists of the eighteenth century. There is the Cartesian method, which distinguishes, separates and analyses, as well as the Leibnitzian method, which tends to compare, to seek resemblances or analogies, to establish continuity. J In one way or another, modern science no longer 
attempts to find laws of finality, as did Aristotelian science, but rather laws of relations and of co-existence. We are no longer dealing with metaphysical origin, nor are we yet dealing with historical origin; our business is to analyse the present state of things, to attain to the conception of it as a system.

If we consider the development of zoology in the eighteenth century and the first part of the nineteenth, we find it dominated by the ideas here indicated. Linnæus, the cele-brated Swedish naturalist, takes as his starting-point the maxim of Leibnitz: Natura non facit saltum. His opinion is that the beings of $\checkmark$ nature must form a chain, as our thoughts do, and that each species must be exactly intermediate between two others. It is the object of science to arrange beings so that this condition may be fulfilled. Such a classification is, of necessity, a unique one: it is the natural classification, and represents the very thought of the Creator. Species, moreover, are fixed and distinct.] They cannot be classified with exactness, unless they are clearly defined. With this end in view, we must take into consideration all the character- 


\section{THE BIOLOGICAL LAWS}

istics which may be offered by animals: external characteristics, anatomical structure, faculties, kind of life ; and from these elements we must form the irreducible types realized by nature.

The principle of Linnæus called forth clearly determined investigations, the very progress of which imperilled it. The number of species increased unexpectedly, and those who described them accused one another of exercising a fanciful imagination. There had to be found for species a definition which was not open to the charge of being arbitrary. They fell back upon Aristotle's definition : interfecundity, a crude fact rather than an intelligible noticn.

Many philosophers, however, both rationalistic and empirical, protested against the claim to reduce the infinite variety of nature to the separations and oppositions of our clear ideas; the very difficulties experienced by the classifiers brought forth investigations conceived in a sense opposed to that of Linnæus.

To Buffon, there are no species in nature; there are only individuals. His watchword is : "War upon systems," that is to say, upon 
classifications within which the mind thinks it can confine the productions of nature. Buffon's views, in this respect, are, above all else, negative. It was Êtienne Geoffroy SaintHilaire, who, combining the idea of continuity with that of order, substituted for classification a philosophy based essentially on the consideration of resemblances. The principle dominating his theories is the unity of plan on which all organized beings are built up. Nature, according to this thinker, has formed all living beings after a single plan, the main features of which are essentially the same, though its details vary considerably. Here, again, we are dealing not with laws of descent, but with laws of co-existence; we are not seeking the cause which produces beings but rather those relations of resemblance which connect them with one another. The principal laws enunciated by Geoffroy Saint-Hilaire may be more or less closely traced back to the principle of the unity of the plan of composition, as thus understood. These are (I) the law of the equilibrium of organs: animals differ from one another only in the degree in which their parts are developed; when certain parts are considerably developed, others, by 
the law of compensation, become rudimentary ; (2) the principle of analogous organs: though considerably modified as to their form and function, organs may be said to remain analogous, so long as both their position and their relation to the other organs remain the same; (3) the principle of connexions : whatever their variations in volume and diversity of function, the parts always retain the same relative positions. An organ is rather perverted, atrophied or destroyed, than transposed. In accordance with these principles, Geoffroy decidedly regarded morphology as an advance on physiology. He affirmed that differences in function and form resulted from the conditions in which the animal happened to be placed. In short, he reduced monstrosities to general laws, showing that they are based on assignable physical causes; and so he established teratology as a science.

Geoffroy Saint-Hilaire is opposed by Cuvier. The former started with the idea of continuity ; the latter declares that he deals with facts alone; he is in favour of discontinuity. He tries to find in anatomy the basis of natural classification, and lays down the principle of ruling 
characteristics. In accordance with these guiding ideas, he rejects the doctrine of a unity of division and recognizes four fundamental planes : that of Vertebrata, that of Mollusca, that of Articulata and that of Radiata. He looks upon interfecundity as the distinguishing mark of a species, though he does more than simply try to find a method of classification. His principle of the subordination of characteristics goes beyond simple description. $\mathrm{He}$, too, seeks for laws of solidarity and of relations. Such is his principle of the correlation of forms, in virtue of which: (I) no part can change without the rest changing also; (2) given the form of one organ, it is possible to calculate that of the other organs. Such, also, is his principle of the conditions of existence, in virtue of which every animal possesses exactly what it needs to ensure its existence under the conditions in which it is placed.

Hitherto, we have seen that nature is considered as a system. Still, from the heart of the Cartesian-Baconian philosophy there arose doctrines the tendency of which was to regard the supreme object of natural science as existing not in immutable order, but in the 
history and genesis of beings. Kant, in his Universal History of Nature and Theory of the Heavens, actually infers the genesis of the world. In the eyes of the philosopher, Schelling and Hegel glorify investigation into historical development, assuming the identity of the logical with the historical order. In France, Condillac sets forth his system of the transformation of sensation as both historical and logical. They go so far as to attribute to the past, not merely an influence over the present, but real causality with regard to it. Hence we have the doctrine of progress, brilliantly expounded by Condorcet in his Esquisse d'un tableau historique des progrès de l'esprit humain. Hence also the idea of historical laws, strictly so called, laws which no longer bind, necessarily, the simple elements of things, but the various phases they present in time. These ideas came to light in zoology, in so far as they were favoured by the results of philosophy which was inclined towards an explanation of the system of nature. Philosophers wedded to the idea of continuity are disposed to say that identity of origin gives identity of type. On the other hand, partisans of the discontinuous are also classifiers. Consequently, they 
NATURAL LAW IN SCIENCE AND PHILOSOPHY

admit that species are not wholly separated, but that they resemble one another in certain of their characteristics. The ideal of classification is the reduction of the diverse to a single principle. But then, may it not happen that beings countenance such a distribution because they have one common origin and have gradually become diversified, like a tree whose trunk is divided into branches more or less distant from one another?

Buffon actually builds up the history of the earth. Not only that, but when comparing with one another the fauna of different countries, he puts forth the hypothesis that numerous species may be reduced to a small number of principal stocks from which all the rest have arisen. It is Lamarck, however, who launches the idea of a genetic explanation of the variety of beings, clearly conceived for the first time in all its generality and means of realization.

Lamarck starts by investigating the lower organisms; here we have the origin of his philosophy. He conceives the higher forms as having sprung from these lower ones, and seeks the explanation of these transformations in the action of environment. 
Environment makes a demand upon the living being, and the latter adapts itself to environment. Lamarck invokes need and habit, as links between cause and effect. The demand gives rise to a need, the need determines a habit, and the habit creates the organ. Modifications are perpetuated by heredity, and so the present diversity of species is explained. The changes that have come about in environment are the original cause of this diversity.

Darwin takes the opposite course. $\mathrm{He}$ starts with the present fact of the discontinuity of species, and purposes to account for this discontinuity by mechanical causes. In contradistinction to Lamarck, he lays it down as a principle that every species is, in itself, plastic. Indeed, it is one of the characteristics of heredity that children are never exactly like their parents. Again, the disproportion between propagation and the amount of food sustenance produces the struggle for life. This latter, in turn, produces natural selection which, thanks to heredity, acts, in time, like our arti. ficial selection. And so Lamarck explains variability by adaptation, whereas Darwin 
explains adaptation by variability; though both are alike bent upon finding an explanation-and that a mechanical one-for the genesis of beings.

At first, no one paid any attention to Lamarck's system. Darwin's speedily met with huge success, but it was not long before gaps were evident. His system does not go back to the causes of the variations upon which selection is exercised. It does not explain why organisms which were found side by side grew up along different lines, instead of proceeding along the same. Contemporary science attempts to fill up these gaps; M. Espinas, in Sociétés animales, and M. Edmond Perrier, in Colonies animales as well as in his Traité de Zoologie, aim at ascending to the very origin of organisms, to the formation of original characteristics, which selection may emphasize or obliterate. Attempts are also made to discover the law of succession itself, or the evolution of forms. With this idea, Haeckel put forward the principle of the parallelism of ontogenetic and phylogenetic develop$\checkmark$ ment, a principle which scientists are inclined to regard as true, in theory, at all events, i.e. 
basing their conclusions on normal embryogenetic development.

To sum up, whereas Aristotle tried to discover laws of finality, and Linnæus, Geoffroy Saint-Hilaire and Cuvier laws of co-existence, the modern doctrine of evolution seeks after laws of causality; $]$ it claims to reach origins, not merely relations of solidarity; this, too, apart from all metaphysical considerations. It looks upon origin as generation in time. Its arguments are: (I) the refutation of the doctrine of separate creations, as being connected with finality and powerless to make out a definite list of species; (2) inductions based on comparative palæontology, anatomy and embryogeny; (3) the effective reconstruction of more or less considerable portions of the genealogical tree. Still, the opposite school does not regard itself as beaten. It invokes facts, and alleges: (I) that it is the evolutionists who introduce metaphysics into science; (2) that, scientifically, the system is only a hypothesis; (3) that, as a matter of fact, the links that are sought for are lacking in a number of cases ; (4) that the only experimental proof of a convincing nature, viz. inter-fecundity changed 
NATURAL LAW IN SCIENCE AND PHILOSOPHY into inter-sterility, or vice versa, is altogether lacking.

In the next chapter, we shall inquire into the philosophical meaning of this contention. 


\section{$\mathrm{X}$ \\ THE BIOLOGICAL LAWS}

(Continuation and End)

$7 \mathrm{HE}$ preceding chapter was given up to an enquiry into the various phases through which zoological philosophy has passed. In antiquity, it was the metaphysical point of view that dominated; species are connected with the principle which, to the mind, accounts for their existence, and this principle is type, as a final cause. The illustrious scientists of the eighteenth and the beginning of the nineteenth century abandoned all investigation into first principles, and purposed more particularly, in their systems of nature, to offer a survey of the logical relations which connected species with one another. In more modern times, the followers of Lamarck and Darwin have again taken up the question of origin, from the historical-not the metaphysical-point 
of view, and they are endeavouring to draw up the genealogical tree of species. What is the philosophical meaning of the contention referring to species?

Here we must beware against confusing the scientific with the philosophical problem. Have species a common origin, and do they descend from one another by way of generation? Thus stated, the question is an exclusively scientific one. Nor let it be said that questions of origin belong to the realm of metaphysics, and not to that of science. This is true of the absolute origin of being, not of the chronological origin of the phenomenon, and it is the latter with which we are here dealing. It may be that the problem is practically an insoluble one ; that, however, is owing to insufficient data, not to the nature of the question. Whenever we are concerned with facts which either have been or might have been observed, it is the business of the scientist to try to discover or infer them. Thus, it is the province of science alone to solve-so far as it can be solved - the problem of production by evolution or of the original separation of species. Philosophy has no part in the solution of this 
question, its business is to investigate the nature of the laws regarded as controlling either the transformation or the permanence of species, and to find out if these laws eliminate all metaphysical ideas, or if they involve, in a greater or less degree, some element that cannot be reduced to experimental mechanism.

On this question there are certain current opinions that are almost prejudices. It is frequently said that to concede fixity of species is to appeal, for an explanation of nature, to the supernatural action of a providence that is the transcendent personification of finality. On the other hand, it is often declared that to maintain variability is straightway to repudiate any doctrine of finality, to adhere to causality strictly so called, and to conform to the true scientific spirit. But it does not seem at all necessary that the doctrine of fixity should imply belief in Providence, or that transformism should do away with every principle of finality. It might even be affirmed that there is something unexpected in these interpretations. Speaking generally, is it not the principle of immutability that is invoked to show that things are self-sufficient and 
have no need of God? Eadem sunt omnia semper, was the motto of Lucretius, when he maintained that the gods do not trouble about the world. To those who ask: Who made things? the answer comes: They were not made, for in essence they are eternal and change not. According to this view, Newton thought that, if the laws allowed of no exception, Providence would cease to be demonstrated. Fortunately the system called for revision, the realization of which testified to the workings and presence of God. Such is the general thought on the matter. But when we are dealing with natural history, everything changes: fixity becomes a sign of finality, and it is change that is regarded as denoting the absence of providential action.

The proof that the interpretation here made of fixity and variability is not inevitable, is that Lamarck, who first advanced the idea of transformism, purposely connected his doctrine with belief in a supreme principle of order and harmony. The scale of beings represents, he said, "the order belonging to nature and resulting, as do also the objects which this order brings into 


\section{THE BIOLOGICAL LAWS}

existence, from the means she has received at the hands of the supreme Author of all things. . . Through these means, which she genuinely continues to use, (nature) has given and is perpetually giving existence to her productions; she is continually varying and renewing them, and thus everywhere preserves the whole order resulting therefrom."1 Again: "Thus, by such wise precautions, everything is maintained in the established order ... ; the progress acquired in improving organization is by no means lost; everything that seems to be disorder and anomaly is continually reverting to the general order and even contributing thereto; at all places and times, the will of the supreme Author of nature and of all existence is invariably being done." 2

How has the habit come about of connecting with the question of variability the idea of a purely natural causality? To begin with, there would appear to be a somewhat futile cause for this prejudice. We read in Genesis

1 Lamarck, Philosophie zoologique, t. I, p. II3, quoted by Perrier, La philosophie zoologique avant Darwin, p. 83.

2 Idem, p. 84. 
that the plants and trees, animals and birds were created, each bearing seed after its own species or kind. This text has been interpreted literally, and the irreducibility of species has been regarded as one with the doctrine of creation. To uphold fixity, then, was to acknowledge a creator ; to deny fixity was to overthrow the foundations of metaphysics and religion, by convicting the writer of Genesis of being scientifically at fault. Nevertheless the opinion in question is based on other foundations also. The Greeks looked upon immobility as being perfection; the reason they thought of God as apart from the world, was that the world, to their mind, was essentially subject to motion. The doctrine, therefore, which connected the fixed with the divine, was a classic one, and it is quite conceivable that this point of view is also that of many thinkers. Still, speaking generally, the moderns are not of this opinion ; they extol motion, life and progress, and consider immobility as akin to stagnation and death.

In a word, neither fixity nor variability, of themselves, denote, nor do they exclude, finality. We must determine more closely 
the conditions of this latter, and see if these conditions are to be found, either in the laws laid down by the partisans of conservation, or in those laid down by the partisans of transformism.

By what sign may we recognize finality and distinguish it from simple causality ? Whenever past facts, strictly observable, suffice fully to explain a phenomenon, the explanation is a causal one. If the past facts are inadequate and appeal has to be made to something which has not been realized, does not yet exist, will never perhaps be fully realized, or which must be so only at some future time, and thus appears only as possible, then the explanation is more or less finalistic.

On the whole, the doctrine of the fixity of species, as supported by its representatives, sets up fewer philosophical claims than the contrary doctrine. It is based solely on observation and experiment, and consists, essentially, in affirming that up to the present, no single fact of the creation or the blending of species has been established. The explanation of this fixity by the operation of Providence is rather an addition to the doctrine than an integral part of it. No 
doubt the order and harmony with environment which we find in species may make one think of some guiding intelligence; but then, they may be affirmed as facts, without any attempt to explain them. Certainly no great value can be attributed to the explanation offered, so long as the consideration of the present state of things is insisted on, without inquiring if this state may be indefinitely extended to past and future. This, indeed, is the attitude of the antitransformist school. It abides by present facts, troubling neither about origins nor future possibilities. And this is why it can give a philosophical bearing to its doctrines only by modifying their character and spirit. Finalistic beliefs, though frequently connected with antitransformism, form no part of it.

Transformism, on the other hand, usually shows itself as a philosophy pregnant with metaphysical, religious and moral consequences; what it purposes to do is to explain the existence and order of species, apart from any finalistic hypothesis. It is this system more particularly that we have to examine. As we have seen, it assumes two forms: Darwinism and evolutionism. Let us examine 


\section{THE BIOLOGICAL LAWS}

Darwinism, the first in point of time and also the more rigorous of the two, from the scientific aspect.

We begin by establishing the present existence of species and their adaptation to environment; but instead of generalizing this fact ad infinitum, in time and space, an attempt is made to explain it, and that historically, by the action of the past on the present, in conformity with the law of inertia. Heredity offers a succession of beings relatively similar to one another ; though, on the whole, they admit of a few slight variations. These variations are looked upon as the startingpoint of the present diversity of species. In cattle-breeding, nature, by the aid of blind forces, effects the same results as man brings to pass by his skill. The struggle for life is nature's substitute for intelligence. Through this struggle there mechanically comes about a natural selection, analogous to artificial selection.

Darwinism, accurately stated, considerably restricts the part played by finality, since the struggle for life on which it is based results from the disproportion between the number of living beings and the means they have of 
NATURAL LAW IN SCIENCE AND PHILOSOPHY

supporting life: a disproportion that is altogether opposed to harmony and fitness. Still, the struggle for life itself implies that every individual has a tendency to live and grow, and that it uses the right means to attain this end; and heredity, established as a fact, though its principle is unknown, possesses the remarkable characteristic of ensuring the perpetuity of the type, through the disappearance of its individual members. Nor must it be forgotten that finality may well be realized by means of very general and constant laws. The main objection to Darwinism, however, is that it offers a gap; for it identifies natural with artificial selection. Now, this identification is possible only if the useful accidental characteristics reach a sufficient stage of development to be capable of being used. At the outset, they are scarcely noticeable and altogether lacking in consistence. Who sustains and fosters them, between the time when they first appear, and the time when they become capable of ensuring the survival of the beings endowed therewith? Does not everything take place as though beings possessed an instinct which makes a more or less vague 


\section{THE BIOLOGICAL LAWS}

choice of the means fitted to ensure their existence ?

However it be, Darwinism is a system that is mainly scientific. It does not claim to explain everything or to be exempt from gaps. Evolutionism, on the other hand, offers itself as a complete system, both scientific and philosophical, in which finality must be wholly replaced by mechanism. The means employed is the establishment between all beings of a dual relationship of continuity and efficient causality. It is thought that this will be done by picturing to oneself the scale of beings as follows : (I) At the lowest stage, we find protoplasm, endowed with irritability. When subjected to excitation, it becomes modified, forming colonies and organisms. (2) The physical and social conditions, in which living matter has been historically found, have determined all the forms it has assumed. (3) All beings come into existence, by way of generation, from protoplasm, and science will build up this genealogical tree with everincreasing completeness, and thus explain the compound by means of the simple, after the fashion of the physical sciences.

This system, being conceived as complete, 
is all idea of finality thereby rendered illusory?

We have succeeded, it would appear, in getting rid of external finality. But there is also immanent finality, another form of it, which, even in Aristotle, by no means excluded but rather required a certain degree of variability.

We invole continuity; but apart from the fact that we do not see why continuity, which is by no means identity, should exclude final causes, we are here dealing only with a very rough kind of continuity which always, when more accurately observed, resolves itself into discontinuity. Indeed, discontinuity is explained by discontinuity: the degree alone differs in elements and compounds. Still, when dealing with the organic world, a slight difference may be very serious.

The sign of efficient causality would be to explain specification and adaptation, which seem to imply finality, by principles in themselves devoid of these two characteristics. But here the element is actually an individual, and reproduces, by heredity, its very individuality. In addition, it possesses within itself an evolutive force, by means of which it adapts itself more and more to the 


\section{THE BIOLOGICAL LAWS}

conditions in which it must live. The result is that the characteristics it is proposed to explain are presupposed in the very elements taken for granted. The difference is only one of degree. In reality, we ascribe to ourselves the power of specification and adaptation, and show how, if circumstances permit, this power passes into action, and realizes the species we have before our eyes. Finality is presupposed by the entire system.

The zoological laws, therefore, are not actually reduced to the physico-chemical laws. In the very systems in which they come nearest to them, they remain separate and original. Indeed, they regulate the order of things in time. The physical laws regulate only relations of cause and effect, one of the two terms being assumed as given. Evolutionism transfers to succession of beings in time the notion of physical causality, which, of itself, relates only to a couple of phenomena taking place at any particular time. It introduces the historical idea of law. According to this system, nature may be compared to a man who is acquiring experience and advancing more and more directly towards his goal. By means of this new type of law, we may conceive, as 
determinate, relations which the purely static sciences left indeterminate. But we are going farther and farther away from the type of necessity. According to the idea of necessity, indeed, the nature of things is immutable, and laws are the relations that result therefrom. Here the nature of things is variable, and laws unite to one another terms that are always modified. More than this: they connect the less perfect with the more perfect. These are laws of progress. Is it still necessity, and nothing else, that gives a new aspect to these laws? Science answers neither in the affirmative nor in the negative, for it by no means reduces the biological to the mechanical laws. Here we are left to the intuitions of our mind. If we believe that the word progress has indeed but a relative meaning, and that, in essence, everything is as good as everything else, we shall believe that matter must have produced life, which, in this case, is nothing more than a word. If we believe that the progress of organization possesses real worth, we shall also attribute worth to the human intellect, which insists on good being an end, and it will cost us no more to 


\section{THE BIOLOGICAL LAWS}

regard nature, from which man must issue, as a step in the direction of human nature, than to regard man, the offshoot of nature, as a grouping together of material elements. If then, when dealing with biology, determinism becomes more confined and restricted, less and less does it coincide with necessity and mechanism. Contemporary philosophy is at fault in having confused the two terms: necessity and determinism. ${ }^{1}$

1 Compare the following lines of Huxley: "It is certain ... that the notion of necessity is something illegitimately thrust into the perfectly legitimate conception of law. . . ." Huxley's Lay Sermons, p. I58.

In his work on Evolution, Professor Calderwood, of the University of Edinburgh, expressed himself as follows: "There is a Power operating continually in Nature, which does not come within range of the observation possible to scientific modes and appliances, yet to which Science is ever indirectly bearing witness." Prof. Calderwood: Evolution and Man's Place in Nature, London, I893, p. 34I. 


\section{XI}

\section{THE PSYCHOLOGICAL LAWS}

7 HERE is not the same degree of precision 1 and clearness in the concepts of psychology as in those of the physical or natural sciences: consequently, before examining the notion of psychological law, [we will go over the main phases through which psychology has passed, and thus the more easily investigate its object and spirit.

At the present time, psychology is mainly concerned with scientific interests. This remark, however, calls for an explanation, for the word, science, has changed its meaning from the one it had in antiquity. The ancients defined science as the knowledge, a priori, of that which is, i.e. of that which constitutes the substratum of things and subsists throughout all change. According to them, this substratum of things consisted in perfect form and final cause. To investigate the 


\section{THE PSYCHOLOGICAL LAWS}

science of the soul, along these lines, was to determine the idea which psychic manifestations tend to realize. The moderns adopt a different standpoint; they determine the idea of science not $\vec{a}$ priori, but from the sciences actually realized. Thus, in Bacon, we come across the idea of phenomenal law or the constant relation between heterogeneous things. Science, in his view; must be practical and establish the maxim that governs production, i.e. it should teach us what phenomenon must be laid down in order that the one we have in view may appear. Here, there is nothing to compel the two phenomena to be reduced to each other in mind: there may be no logical connexion between them. Descartes, on the other hand, taking as his type not material production, but rather mathematics, or ideal production, thinks that exact science consists in starting with rationally simple elements, and composing, from these elements, by rational deduction, wholes which, as regards essentials, are similar to the objects offered us by experience.

Now, whether we take Bacon or Descartes 
as our guide, it would seem a difficult matter to set up psychology as a science. Will the Baconian laws, which consist of constant relations of co-existence or of succession, be included in manifestations whose complexity seems infinite, and their impermanence essential ? On the other hand, can a mathematical explanation, such as Descartes requires, be applied to what does not seem amenable to measurement? Seeing that Science is looked upon as either an ensemble of physical laws or a chain of mathematical demonstrations, it is a paradox, so to speak, to expect to set up psychology as a science. And yet the moderns have done all they could to effect this. Let us look at the results of these efforts.

[It is in the philosophy of Descartes himself that we find the first elaboration of psychology as a science. Descartes makes a distinction between the domain of science and that of extension. This latter is the peculiar object of science, whereas mind is its artisan. To become an object of science, therefore, the mind must be regarded from the standpoint of extension.] If we are dealing with the essence of the soul, this condition is impossible I6o 
of realization. Apart from thought and extension, however, Descartes admits of the union of soul and body as an irreducible reality. From this union, there result, in the soul, accidental modes relating to extension, and which may be regarded from the standpoint of extension. Knowledge of these modes may be scientific in the same way as knowledge of sensible phenomena. This knowledge relates to physiology, which is no more than a complex aspect of physics.

The Cartesian conception is a very clear one, though it gives rise to difficulties that were soon noticed. In the first place, it removes from science, strictly so called, under the name of pure thought, a considerable portion of psychic life. Then it raises the question as to the right by which there is substituted for the psychical phenomenon, strictly so called, i.e. for the modification of which we are conscious, a wholly heterogeneous external phenomenon. The solution of this difficulty takes up the whole of Cartesian metaphysics, culminating in confidence in divine truth. It is this problem of the relation between soul and body, implied in the claim to make the latter the standard 
of the former, that finds a response in the learned though transcendent hypotheses of occasional causes, unity of substance, preestablished harmony. Here science is justified, though really by belief. Thus, the correspondence postulated by Cartesianism could be neither rigorously defined nor demonstrated; it remained founded upon the God, the common principle of soul and body, to which Descartes had appealed. But whilst the Cartesians were using their utmost efforts to find in the body the faithful expression of the soul, others tried to discover in the soul, considered apart, the elements of a scientific "psychology. These were the English philosophers. They started with the Baconian idea of natural law and combined this idea with Cartesian principles.

Locke regards a distinctively psychic element, the idea, as lying at the root of the science of the soul. Ideas form the counterparts of material atoms. They are definite, impenetrable units, external to one another, and are brought into the understanding by experience, without the intervention of any intellectual activity. They cannot collect of themselves any more than atoms can; but 
whereas the collecting of the latter takes place by means of natural forces, that of ideas is artificial ; being due to the activity of the human mind. Combining or separating the ideas that come to it, the understanding converts them into a structure which forms the fabric of our knowledge.

In Locke, we have dualism : the arrangement of ideas or materials comes about, not of themselves, but through the activity of mind : the architect.] As it developed, this philosophy became dual : two groups of doctrines correspond to the two elements of knowledge, distinguished by Locke.

The first direction it took is represented by the philosophers who may accurately be termed Ideologists. They attempt to build up the whole of psychology from ideas alone. Their concern is to render of none effect all that Locke did with the object of grouping ideas. To discover more and more completely in ideas themselves the cause of their connexion: this is the direction of the progress of these doctrines. For instance, Berkeley shows that there exist distinctively psychic laws: the visual perception of distance cannot be explained 
by a necessary inference obtained, without having recourse to experience, by means of visual geometry. It consists of the suggestion of tactile perceptions produced by visual perceptions, within the imagination and through experience. The various perceptions have thus the property of suggesting one another, in spite of their mutual irreducibility; consequently, this suggestion is contingent. Here is an instance of a psychic law conceived in an ideological sense. This idea of psychic law, as a substitute for the spiritual activity of Locke, forms the groundwork of Hume's philosophy. By the aid of mental impressions and the laws inherent in them, Hume thinks that the entire system of our knowledge can be explained.] Impressions, as they weaken, become ideas. These ideas associate of themselves, according to relations of resemblance, contiguity and causa-

$\checkmark$ tion, causation being nothing but the tendency of an idea to call forth a heterogeneous idea with which it has frequently been associated. Bodies, likewise, according to Newton, attract one another in accordance with a law by which only their mass and their distance are taken into account. Here we have no longer I64 


\section{THE PSYCHOLOGICAL LAWS}

a duality of mind and idea, as in the case of Locke, since the psychological laws are but relations that result from the nature of the ideas themselves. And yet, the notion of tendency, i.e. of the habit of imagination, to which Hume appeals, has something mysterious about it. - Whilst founding or basing this habit upon kindly nature, Hume endows it with a kind of objective value. John Stuart Mill endeavours to eliminate even more completely every trace of activity. By the mere force of ideas, an association becomes inseparable, if it has often been reproduced and never contradicted.] Association, taken literally, that is to say, a law analogous in all points to the physical laws, must explain all those concepts and processes which it has been deemed necessary to attribute to spontaneity of mind : viz., causality, first truths, reasoning, will, morality, exteriority, body and mind.

Such is the development of Locke's philosophy, conceived in an ideological sense. It raises a certain number of difficulties. What is this given: the starting-point of the ideologists and the thing by which they endeavour to explain the entire psychic life ? The atom-idea 
NATURAL LAW IN SCIENCE AND PHILOSOPHY.

is no clearer a concept than the material atom. Is it true that there may be psychic indivisibles, when we are unable even to find a corporeal indivisible? And if we analyse this pretended given: the idea of the ideologists, do we not always find in it, along with an element that has been introduced from without, that very mental activity we purposed to eliminate? What is the value of a doctrine if its principles take for granted the one thing it claims to dispense with? Thus reason the second category of Locke's followers, whom we may designate as the "dynamist" psychologists. Moreover, amongst the dynamists, we may distinguish those who proceed by analysis and those who proceed by simple observation.

Condillac may rightly be included amongst the representatives of analytical dynamism. Indeed, the sensation which he posits as primal and fundamental is no mere indivisible, inert datum; it is a faculty, and develops by reason of the activity proper to it. This activity consists in analysing itself, and thereby becoming diversified and transformed into higher and more special faculties. The greatest representative of analysis, however; 


\section{THE PSYCHOLOGICAL LAWS}

is Kant. He regards it as impossible to explain the judgment of existence, implied in all experience, unless we admit that the mind is originally active. In spite of everything, then, this activity is to be found at the root of all that is called given. The given, pure and simple, is nothing but a chimera. The only given is what the mind gives itself when it assimilates the materials supplied by the outside world. Thus was formed, by the use of the analytical method, the so-called "faculty" doctrine.

Along another path, by interior observation followed out as far as it could possibly be carried, the Scottish philosophers reach similar results. Reid discovers, by a process of introspection, that external perceptions, which Locke interpreted as simple ideas, possess three elements: sensation, the conception of an external object of which sensation is the sign or mark, and immediate belief in the present existence of this object. Now, this belief is a primitive judgment formed in virtue of fundamental psychic laws, called the principles of common sense.] Following on Reid, Jouffroy thinks he perceives, beneath phenomena, the faculties that are the govern- 
ing factors in them ; and beneath the faculties, the very substance which possesses these faculties. He arrives at apriorism by observation pure and simple. Whether it be, then, by the method of observation or by that of analysis, something besides facts is obtained. Over against associationism stands apriorism in the development of Locke's philosophy. The two principles this philosophy had brought together have become dissociated and antagonistic to each other.

$\sqrt{\text { We }}$ have seen that the mathematical psychology of the Cartesians was incapable of firmly establishing its position. Will the psychology of introspection, which originated with Locke, suffice for modern philosophy, which investigates the science of the soul ? Dynamists and associationists are engaged on a problem which, on the ground of interior observation alone, seems impossible of solution. Experience presupposes principles à priori, say Kant's followers. I can explain your principles d priori by experience itself, replies Mill. Both sides accuse each other of arguing in a circle. Besides, neither doctrine, in itself, really fulfils the conditions of science. The dyna- 


\section{THE PSYCHOLOGICAL LAWS}

mists are reproached for an apriorism which goes beyond the bounds of science and admits of no definite relation to facts. On the other hand, when associationism itself comes to be completely formulated, it acknowledges its own inadequacy. The self indeed, according to this doctrine, would appear to be only a series of conscious states, a series that knows itself. But then, how can a series know itself, i.e. unify itself ? Whence comes the bond between them ? Mill himself agrees that this unity cannot be a simple product of the laws of thought, and so he appeals to the Self.] On the other hand, the connexions between psychic phenomena which can be discovered by interior observation remain extremely loose and indeterminate. The ideologists postulated that ideas form a world apart, one which has its own laws, like the world of bodies. But is the psychic thus self-sufficient? This does not seem to be the case, and so associationism, which deals only with states of consciousness, may well be descriptive, though not explanatory; or, anyhow, it can offer none but the vaguest and most general explanations.

In presence of the gaps, irremediable, it I69 
may be, in the psychology of introspection, the Cartesian idea of the explanation of the soul by the body has again been advanced. Has man any other means of knowing scientifically than through matter? May not matter be just the form-and nothing else-that mind gives to things when attempting to attain to a knowledge of them ? To try to find in external, measurable things, the expressions and substitutes of mental affections: such is to be the spirit of the investigation we now have to examine. But the psychologists will endeavour to avoid the difficulties which compromised Cartesianism. This latter evidently wished, off-hand and once for all, to ensure that the psychic corresponded with the physical ; to do this, it plunged into the most difficult metaphysical investigations. The moderns, gradually and in the light of experience, will endeavour to set up a series of relations between physical phenomena and psychic phenomena, considered in detail.

Bain remained a Scotchman, in many respects. All the same, he assimilated the new tendency, when he conceived of observation in a way that combines external 


\section{THE PSYCHOLOGICAL LAWS}

with internal observation. According to him, if we would attain to the real, and not merely to something abstract, we must consider the psychic fact in its natural totality, and never isolate the internal element from its physiological and physical concomitants. To study both terms in their conjunction, is the method to be followed.

Spencer, in one vast synthesis, appealed to the infinite, and intercalated, between the psychic and the physical, an infinity of intermediaries, which enabled the former to be conceived as a product of the latter. $\mathrm{He}$ considered that the psychic has its explanation in the physical, in so far as even the most complicated mental phenomena are gradually reducible to reflex action and in so far as this evolution itself has for its principle the growing correspondence of the organism with its environment. Adaptation to external conditions is thus the common characteristic both of the life of the soul and of that of the body. The laws of the body are simpler; those of the soul, more complicated. Again, whereas changes in the body are both simultaneous and successive, in the soul they are only successive. The essential constitution of the 
soul is the property of perceiving a difference ; it is the specification of this property that causes all its faculties to appear.

[Thus, whereas Spencer regards as legitimate the point of view of external observation in psychology, professional scientists enter upon the problems in detail, after the fashion of the physicist or the naturalist.] The question with them, as with Descartes, is to find the exact angle, so to speak, from which things may be known scientifically.

[ It was with this idea that Fechner sought for the mathematical relation between excitation and sensation. His law is strictly scientific in form, but it is difficult to bring it into perfect accord with minutely observed facts, and so to determine, with certainty, their psychological signification. He brought the psychical into direct contact with the mathematical.] It is more prudent to intercalate intermediaries, and these are supplied by physiology. Hence we get experimental physiological psychology. In accordance with this discipline, the psychic element is grasped-and will be for a long time yet-only by consciousness; still, we are entitled to acknowledge that it corresponds 


\section{THE PSYCHOLOGICAL LAWS}

to a physiological process which is connected, according to the general laws of physiology, with observable physiological processes. Indeed, the phenomena of nerve-transmission, which are undoubtedly phenomena of material motion, are not known by consciousness. It may, then, be the case that thought also is accompanied by movements, without our being aware of them. And so, between the impression from without and the corresponding visible action, it is natural to admit of a continuity of physical phenomena. The psychologist, then, seeks to become acquainted with psychic acts through their observable physical and physiological antecedents and consequents. He sets up relations of cause and effect between physical phenomena and states of consciousness, until these latter are themselves known in their immediate material substratum. FAnd, according to Descartes' method, experimental psychology proceeds from the simple to the complex: at first, it purposes to measure the duration of psychic acts, from the most elementary, which is simple reaction, to the most advanced, such as the perception of difference, the action of counting and naming, 
and the increasingly complex process of reasoning. Thus, it gradually extends its domain ; and, where experimentation cannot yet find scope, it is content, for the time, to be descriptive, as Bain meant it to be, when taking into consideration not only sane states but more particularly morbid ones, which are, as it were, experimental decompositions of the phenomena wrought by nature herself. What is it that this psychology desires? Its founders, Helmholtz and Wundt, without mentioning Fechner, do not profess to eliminate all à priori elements. Helmholtz admits causality in the Kantian sense. Wundt superimposes on the mechanism of the lower functions an intellectual activity which uses this mechanism to realize ends proper to itself. Several are inclined to go further in this direction. Beaunis, however, is of opinion that, for the time at all events, we must neglect moral phenomena and all that seems to be the special characteristic of man, and confine ourselves to a consideration of the psychic phenomena common to man and animal alike.

EIt now remains for us to examine the philosophical signification of the psychological laws. 


\section{XII}

\section{THE PSYCHOLOGICAL LAWS}

\section{(Continuation and end)}

$\triangle$ FTER reviewing, in the last chapter, the $A$ various methods relating to the determination of the psychological laws, we have now to estimate the results to which these methods may lead. Of the two main types of psychological laws which we have recognized, the first, the ideological type, is analogous to the physical laws, mutatis mutandis, i.e. it sets up a connexion between terms of the same nature, these terms being, in the present instance, states of consciousness. This conception of the psychic law dates back, more especially, to Locke. The laws of the second kind, those that have their first model in the Cartesian doctrine, set up a relation between a psychic phenomenon and a physical one. From this point of view, it is hoped not only to constitute psychology as a science analogous 
to the physical sciences, but also to bring it expressly within the domain of the sciences of nature.

Now, of what do these two kinds of laws consist? Are they really of the same nature as the laws of the sciences that deal. with matter? Can they comprehend psychic reality without appealing to any notion of activity? In what way is a soulless psychology possible and how far does its influence extend ?

$\checkmark$ [Let us first consider the ideological laws, or the laws of psychic associations. To establish such laws, Locke and his followers must have brought psychic facts before their mind in an altogether artificial manner. To them, these facts are indivisible elements bound to one another from without, like the elements of matter in atomism. ] But how is it possible to bring before the mind, to conceive of an indivisible psychic element? In this order of things, where are fixed, definite materials to be found, set alongside and yet distinct from each other, like the stones of a building? Properties of this kind are shown by words and letters. The associationist psychology takes the data of lan- 


\section{THE PSYCHOLOGICAL LAWS}

guage for the elements of the inner life, of which they form only a rough image.

But, it will be urged, do not the most perfect sciences presuppose artifices and symbols? Certainly, and these latter are justified by the services they render. For instance, $\sqrt{\text { in }}$ chemistry, the atomic hypothesis leads to consequences which can be confronted with facts, by means of definite experiments. In psychology, there is nothing of the kind, for it is not possible to build up a mechanical collection of ideas and compare with facts the results of a strict deduction.] Here, synthesis merely reproduces a more or less exact and searching analysis. Demonstration is never anything else than illusory.

Taken for what they are, i.e. for simple metaphorical interpretations of psychological relations, the laws of association have the disadvantage of being strangely vague. They seem to be realized because they imply objects of knowledge to but a slight extent. One idea is, speaking generally, preceded by another; and as associationism requires not the faintest logical connexion between two ideas for one of them to be proclaimed the cause of the other, so we are always en- 
titled to set up the antecedent as the cause, and explain by simple association the appearance of an idea. The system supplies tables of cases in which a relation of causality takes place, but it neglects to do so in cases where this relation does not take place. How many ideas are contiguous in consciousness without being associated with one another! We must also assure ourselves that explanations by association, which we all like to give, are not simple products of the imagination, inventing, in accordance with its tastes and habits, some romantic episode, the denouement of which coincides with the state of consciousness to be explained.

Again, not only do the laws of association remain vague and hypothetical, but cases happen in which they are clearly inadequate to explain the phenomena. These are the cases, evidently numerous, in which unconscious or physical influences are intercalated between the states of consciousness. For instance, consider the ideas due to impulsions. Are they to be explained by other ideas? Is not the reason for them rather to be sought in organic conditions? If the unconscious and the physical play a rôle in the produc- 


\section{THE PSYCHOLOGICAL LAWS}

tion of our ideas, consciousness can grasp only scattered fragments, it lacks middle terms to connect them with one another.

The laws of association, artificial and hypothetical, vague and superficial, are incapable of founding a system of determinism. Even when successful, they cannot go so far as this. It is a mistake to think that an action is known to be necessarily determined solely because it can be foreseen. Why should not habit and character, feeling and even will produce mechanical uniformities? The inhabitants of Königsberg were wont to set their watches to the time of Kant's usual daily walk.

[In an attempt to fill up the gaps inseparable from associationism, physical psychology considers the soul in its relation to the body. It expects to superimpose a truly scientific psychology on to descriptive psychology by studying the psychic phenomenon in all its elements and conditions, and trying to explain the conscious by the mechanical.

Let us first consider the negation implied in this method. Physical psychology denies the efficacy of the will-act as such. Is this negation legitimate? ' It offers itself before 
us, at the outset, as a plea in bar. Physical psychology, it is declared, proceeds like chemistry or physics : it neither affirms nor denies free-will; it ignores it as being outside its domain. We have to find out, however, whether this voluntary ignorance is as legitimate, in psychology, as in the preceding sciences. The latter deal with phenomena very far removed from mind, and perceptibly isolable from the manifestations of will. Their domains are fixed by definitions that retain something of the freedom of mathematical definitions. If the physicist meets with facts which do not come within the circle he has traced for himself, he relegates them to other seekers. Can we likewise, when entering upon the study of the soul, announce that we will trouble ourselves about nothing that manifests a will which is free ? Are we not running the risk of imposing on nature a delimitation it does not admit ? As regards the sciences that deal with matter, events have shown the legitimacy of the method. Physical psychology; however, is not sufficiently advanced to call for such an argument. We must possess satisfactory proofs that free-will does not in- 


\section{THE PSYCHOLOGICAL LAWS}

tervene in the production of phenomena.

True, it is believed that we possess these proofs. The impossibility of the effective existence of free-will has often been very powerfully demonstrated. All these demonstrations rest, ultimately, on Spinoza's argument, which regards consciousness as being, in reality, nothing but the faculty of transforming into final causes the efficient and mechanical causes unperceived as such. This, however, is rather a very ingenious hypothesis than a genuine demonstration. [In order really to reduce free-will to mechanism, it would be necessary to offer a mechanical explanation of the sense of free-will; and, in order to be in a position to offer such an explanation, all the less complicated psychic phenomena implied in the sense of free-will must have been explained mechanically. These demonstrations also would have to be based on brain knowledge, not on metaphysical hypotheses. - Still, if even the most elementary sensations cannot yet be completely explained by the brain, how can such be the case with the sense of free-will ? ]

This is all we can say with regard to the negations implied by any physical psychology 
that claims to go to the root of the matter. Let us now look at the positive side of the doctrine, viz. the type of law which it has in view. This type of law consists in the dependence of the moral on the physical.] This dependence, however, may be understood in two ways. In the first place the law connects a mental with a physical phenomenon, linking together two heterogeneous terms by a connexion of constancy or invariability and of necessity. A law of this kind has been quite conceivable ever since Hume formulated the famous principle: "Any thing may produce any thing." But if both terms are entirely distinct in nature, their conjunction is to us a simple concomitance; and, à priori, we have no ground for affirming that the physical cannot depend on the psychic, as well as the psychic on the physical. Consequently, the enunciation of such laws is, speaking generally, nothing more than a stage that we hope to transcend. By the dependence of the moral on the physical, we really mean the reduction, as completely as possible, of the moral to the physical. This reduction would be realized by showing that to each psychic phenomenon there corresponds a determinate physical one, and 


\section{THE PSYCHOLOGICAL LAWS}

that this latter can wholly be explained by physical causes. The psychic would thus be no more than an expression, a translation, in a special language, of certain physical phenomena.

To bring about this reduction, the psychophysical measures mental states, and attempts to discover the law of their correspondence with certain physical phenomena. Compelled, however, to substitute, for the sensations themselves, the smallest perceptible differences, it takes for granted that differences as small as possible are equal. Now, there is nothing less evident than this ; Ewe look in vain for psychic units susceptible of addition or subtraction like mathematical units.

Still, this criticism is not decisive. It is not necessary that psychic phenomena should be treated as quantities for them to be reducible to physical phenomena. It is sufficient if each of them, however heterogeneous with regard to the rest, is connected with a determinate physical phenomenon. But here we encounter certain difficulties set forth above. If we insist on some particular mechanical equivalent representing each mental state, 
we admit that the latter are, in a way, fixed and rigid entities, immutable atoms ; a state of things which, as we have seen, is not really the case. Qualities cannot be set outside of one another like material things. It is impossible for us to say where one ends and another begins : they are insuperably complex and fluid.

This, then, is the dilemma which confronts the psycho-physical : either the psychological laws connect heterogeneous terms with one another, and then there is no reason why the former should depend on the latter rather than the latter on the former; or they bear only upon homogeneous and quantitative terms, and in this case it is impossible to establish the correspondence between these objective laws and the subjective phenomena of the soul.]

The fact is that the problem before physical psychology is a paradoxical one. [The positive sciences, from mathematics to natural history, could be constituted only by dividing reality into two parts : the one capable and the other incapable of being quantified.] Since the second part excludes precision and calculation, it may be neglected; the first alone will 


\section{THE PSYCHOLOGICAL LAWS}

be the object of science. $\sqrt{\text { Now }}$, this residuum, which the preceding sciences have had to eliminate in order to become positive, viz. the sum total of the subjective elements, is what physical psychology insists on knowing scientifically. This point of view is the reverse of that of the sciences. There are, then, two alternatives: either we mean absolutely to reduce the within of the phenomena -which the sciences had held in reserveand this reduction will, metaphysically, have a retroactive influence on the sciences. It will convert their objects into baseless abstractions. Scientific concepts, intelligible as a measure of reality, will lose all meaning, if we insist on the measure finally measuring nothing but itself. We shall thus land ourselves in nihilism. Or, as the second alternative, we shall follow the solution only up to a certain point, as the sciences do.] In this case, the science that will be built up, will be as legitimate as the rest. Like these, however, it will leave spirit subsisting, and with it the possibility of a spiritualistic metaphysics.

In conclusion, psychology will be singularly restricted and limited, if it really eliminates 
all notion of soul, and refuses to accept a special postulate. Indeed, the notion of soul is constantly intervening in the so-called mechanical explanations of phenomena that are offered. In effect, the reactions we attribute to psychic being are not simple reflexes, fitted to realize life. They are calculated to bring science into being, and, through science, the rule over things. The being that is endowed with a soul, is not simply a given end, like the being that is endowed with life ; it is capable of proposing an end for itself and imagining means fitted to realize it. It may propose as an end, not only its own existence, but an infinite number of objects which have little or nothing to do with it. It may go so far as to propose absurd ends, such as a state of nothingness. If this be so, there are two psychologies, as it were, though the distinction between them is not very definite. There is the distinctively human psychology, which cannot leave out of account the faculty of reflection that constitutes man. And there is also animal psychology, within the sphere of which enter the psychic manifestations of man himself, in so far as he allows the forces within him to act, without directing them. And I86 


\section{THE PSYCHOLOGICAL LAWS}

the mechanism which this second psychology determines is not unconnected with the freedom revealed by the first. It represents the instrument upon which freedom is immediately exercised, and which brings it into relation with nature. 


\section{XIII}

\section{THE SOCIOLOGICAL LAWS}

HOW has sociology been established?

1 What are the principal stages of its historical development? Greek antiquity, along with Aristotle, declared man to be a political animal. In what sense? Modern naturalism is only too ready to criticize the definition. Aristotle, however, gave it a meaning related to the whole of his philosophy

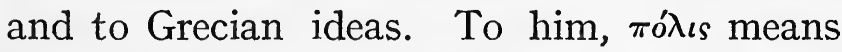
"city-state," not society in general. Moreover, nature does not signify causality, pure and simple, the necessity immanent in things, but rather finality, i.e. the perfect form, the finished type, towards which beings tend to

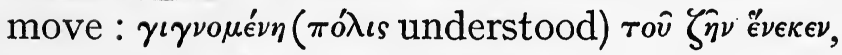

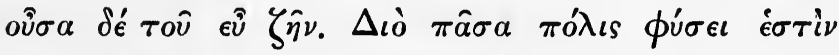

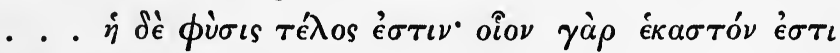

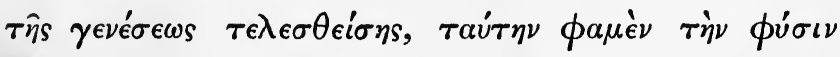

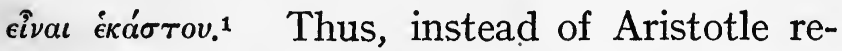

1 As the "city-state" came into being for the sake I88 


\section{THE SOCIOLOGICAL LAWS}

garding nature as the opposite of art, as contemporary naturalism supposes, nature and art form but one at the root of things; nature, the artist, tends to realize an ideal : the "city-state," and the forms that human society assumes are, in effect, the result of this tendency, more or less gratified or opposed.

Amongst the moderns, of whom Descartes is the pioneer, the scientific spirit holds sway. Even social questions are to be dealt with in a strictly rationalistic sense. Descartes dismisses them as irreducible to mathematical evidence. But Hobbes finds the way to deal with society from a scientific point of view and in accordance with the mathematical method itself. He starts with the idea that social organization is a reflective work (artefact) of the human reason, analogous to material machines. Once then, we have determined the precise object of social organization, this latter may mathematically/

of life, so it continues in being for the sake of good life. Wherefore every "city-state" is in being by nature itself. . . . But its nature proper is a perfection or completion. For what every thing is when it has reached its perfection, that, we say, is its true nature.-ARIsTOTLE, Politics, I, 2, I252, b. 29, etc. 
be deduced from human reason. Now, according to Hobbes, it is the property of man to be intelligent; his intellect makes an egoistic being of him: homo homini lupus. Hence we have war waged by all upon all. When this phenomenon happens, human reason necessarily has a conception of the general good. Then it is confronted with the problem of realizing the general good by taking, as agents, beings whose essence is egoism. Hobbes solves this problem deductively. Observation and reason have supplied the principles, the mathematical method deduces the consequences.

Montesquieu's method is also largely mathematical. His starting-point is the nature of man in a pre-gregarian state of existence. This nature inclines men to unite. As soon as they form societies, however, they lose the sense of weakness which they had at first; the equality that existed amongst them ceases, and a state of warfare begins. The problem consists in organizing society so as to regain, within this new state, the primitive state of peace and freedom. Deduction determines the conditions required for the attainment of this result. It remains to apply these principles to the 


\section{THE SOCIOLOGICAL LAWS}

various cases that present themselves in the world, just as the mechanician applies the principles of his science to the various forces offered him by nature.

Rousseau starts with the state of society in his time; in it he sees nothing but oppression. Man, he says, is born free; and he must be free. Whence comes the actual contradiction? In all probability, says Rousseau, men had to defend themselves against causes of destruction, and in presence of these difficulties and drawbacks individuals felt themselves too weak. Possessing no capacity whatsoever for generating new forces, but only for uniting and controlling the existing ones, their only means of self-preservation was to form, by a process of aggregation, a sum total of forces capable of overcoming the opposing force. This collective force, in turn, could only be constituted in accordance with a tacit contract, by which each member, in order to preserve his existence and freedom, transferred all his rights into the hands of the community. Some, however, diverted the force to their own advantage. The problem consists in really organizing society on the idea of the original contract. 
From Hobbes to Rousseau, then, we find society regarded as a work of art, art being clearly distinguished from nature.

From the eighteenth century onward, a third point of view is met with. Those who maintain the doctrine of progress purpose to show that the natural course of things brings about, of itself, the progress of knowledge, and that the latter is inevitably followed by the progress of morality and of happiness. This, according to Condorcet, is the effect of a natural law, independent of the human will. Rousseau, on the contrary, maintained that the progress of science, when pursued for its own sake, diminishes happiness and corrupts mankind; this it does by a law of nature. The Economists assume that men, in a state of nature, were in possession of freedom and property as indefeasible rights. Governments have more or less robbed them of these rights under the pretext that individual freedom would be incompatible with public interests. The Economists purpose to show that, according to the laws of nature, private and public interests, far from being opposed, take each other for granted. Here, then, we have the idea of 


\section{THE SOCIOLOGICAL LAWS}

natural law present in social science; but the publicists just mentioned have assumed beforehand, in accordance with their desires, the very laws they require to discover in the natural course of things.

Auguste Comte was the first who clearly hit upon the idea of a sociology analogous to the rest of the sciences. He regards a social law no longer as the expression of a pious wish, but rather as the expression of impartially observed facts. [Society, however, in Comte's mind, retains a nature of its own, one that is irreducible to the lower forms of being. To Herbert Spencer, on the other hand, human society is nothing but one particular instance of animal society.] Still, why does Spencer uphold individualism as an end for society? Is it not that he makes synthesis follow too closely upon analysis; that he is governed by personal preferences? Many, nowadays, maintain that the true method is . impartially to study the lesser facts, trace their laws in accordance with the general rules of induction, and rise to general views only by degrees. This is the completion of the third conception: society considered 


\section{NATURAL LAW IN SCIENCE AND PHILOSOPHY}

as a natural work, to the total exclusion of the idea of art.

Let us now examine the notion of sociological law as resulting from this evolution, and enquire whether it corresponds exactly with the nature of things themselves.

We first note that naturalist sociology runs paralleI with an exclusively experimental psychology. Just as the latter would explain psychological facts by leaving the soul out of account, so the former would account for sociological facts by eliminating man. It refuses to have recourse to a strictly human faculty, to conscious, reflective finality. To explain phenomena, it is declared, is to condition them to the law of efficient causes. If sociology, then, would be a science like the rest, it must connect facts with conditions, not with ends.

Admitting that sociology must be a science, in the narrow acceptation of the word, what form will it take? At the time when the mathematical sciences were most developed, it was required that this form should be a mathematical one. At the present time, when the natural sciences are soaring to wonderful heights, it is they 
that are set up as models. In this we see a historical influence, rather than a necessary phenomenon. Why should not sociology demand particular postulates and a method of its own, as Auguste Comte required ? It is not sufficient to say: sociology must assume such or such a form; only on this condition will it be science. Is science a single indivisible entity, and may there not be really different sciences, each with an originality of its own?

Now, what is the nature of the laws in which sociology culminates? To assume so called historical laws appears to be the least hazardous attempt in this direction. It is the characteristic of these laws that they connect the present with the past along the lines of efficient causality. The idea is clear enough, but when we pass from theory to' practice, we encounter difficulties. The method consists in explaining social facts by their historical antecedents, whilst eliminating all human initiative; but the question of causality, human or mechanical, is propounded anew with regard to these very antecedents, and so on ad infinitum. From the fact that I, for my own part, merely follow the 
impulsion given me by my ancestors, it by no means follows that my ancestors were as passive as myself. Speaking generally, the necessity of the consequences does not forejudge that of the origin.

But if we waive the question of origin and consider the so-called historical law in itself, we find that such a law is not regarded by men as necessitative. Quite the contrary, we hear them say: such or such a nation, under conditions analogous to our own, has been afflicted in such or such a fashion: let us see to it that a like misfortune does not befall us. In questions of this kind the antecedent is never considered as necessarily compelled to entail any one consequent to the exclusion of any other. An antecedent is regarded as an influence, not as a cause strictly so called.

We may go further and enquire whether there really are historical laws. It is noteworthy that professional historians find some difficulty in affirming this. Fustel de

$\checkmark$ Coulanges was wont to say that in history it is sometimes, though very seldom, possible to determine causes, but that all idea of discovering laws must be abandoned. InIg6 


\section{THE SOCIOLOGICAL LAWS}

deed, according to his view, a law implies the reappearance of one and the same antecedent. Now, where do we find history repeating itself? The essential feature of the historical mind, Jules Zeller was fond of saying, is the discernment of the characteristics peculiar to each epoch; we are generally mistaken when we judge the past by the present, or vice versa. Historical facts are too complex and unstable intermixtures to be reproduced as they are. If they exhibit laws, it is in their elements, not in their concrete sequence, that we must seek them.

Hence we have a second point of view, which may be called the physico-sociological: we endeavour to connect social facts, not with their equally social antecedents, but with external conditions that are capable of being observed and measured, such as geographical circumstances, density of population, amount of sustenance. Here, however, a distinction must be made. Population and amount of sustenance are not crude facts like climatic conditions. Man, the social human being, intervenes in the former class of conditions: therefore they are, to a certain extent, social facts; 
to demand from society an explanation of them is partly to take for granted what we purpose to explain.

Nor is this all; we require that social phenomena, as well as physical phenomena, should derive from external conditions; but it is very difficult to demonstrate this derivation. Suppose, for instance, we explain the development of the division of labour by the progress of social density, the interdependence of the members of a society. The saying of Darwin is recalled, that different beings live side by side more easily than similar beings: they inconvenience one another in a less degree and the struggle for life amongst them is not so keen. Man obtains this salutary diversity by developing division of labour, and so this division of labour shows itself as the necessary result of the struggle for life. Vital competition: a physical cause, thus explains division of labour: a social fact.

But does the law stated by Darwin necessarily apply when we are dealing with man ? Is it correct to say that, in a human society, diversity of functions is invariably a principle of mutual tolerance? Look at capital and 
labour: the difference that separates them does not prevent them from combating each other. It often happens that diversity of education and occupation inclines men to misunderstand and despise one another. If men are to agree, it is not enough that they cannot understand one another.

Let us admit, however, that division of labour is a solution of the struggle for life. In what way will this antecedent determine this consequent? Have we here some relation of necessity, similar to that which connects the attraction of bodies to their mass and their distance from each other ? Division of labour appears to be necessary, if men are to live at all. But here, necessary means indispensable, i.e. a condition of the realization of a certain end, viz. the cessation of the struggle for life. This is by no means a mechanical and inevitable necessity. Must we even translate, in this case, the word necessary by indispensable? The struggle for life, indeed, admits of other solutions, the simplest of which is the eating of one another. That is really the law of nature, and division of labour is instituted for the very purpose of impeding 
NATURAL LAW IN SCIENCE AND PHILOSOPHY

the fulfilment of this law. Indispensable, then, in turn, really means, preferable, i.e. more in conformity with the idea of humanity, responding more completely to that sympathy with the weak which we assume to exist in man. As Aristotle said, we do not wish merely $\zeta_{\hat{\eta} \nu}$, but $\epsilon \hat{\jmath} \zeta_{\hat{\eta} \nu}$. Division of labour is a more or less intelligently conceived means of realizing this ideal. What does this mean, except that what we took to be a crude law of causality involves a relation of finality, and that we are assuming the intervention of the human intellect and will where we think we are bringing into action none but external and material conditions ?

Thus the physico-social law does not satisfy the conditions of a strictly positive science. To bring sociology really within the sphere of the physical sciences, we should have to discover, for social facts, legitimate substitutes, in their mechanical equivalents. The physicist therefore looks upon physical agents only in their measurable manifestations. But do such equivalents, so difficult to find in psychology, exist in sociology? We imagine that statistics will supply them, but do not 


\section{THE SOCIOLOGICAL LAWS}

statistics constantly need to be supplemented by judgment? Where do we meet with figures that admit only of one interpretation, and immediately express the social reality with which we are dealing? Is the number of persons who can read and write a faithful standard by which to judge of the development of instruction in a country? Can religious feeling be gauged by the business carried on in the various articles used in public worship? It is a fact that, in this order of things, men of tact and experience, by means of literary descriptions and without using figures, often hit upon a truth which cannot be acquired by mathematical quantification. If some day we succeed in bringing social facts within the scope of physical facts, it will be by intercalating between the latter and the former an infinite number of intermediaries of whose existence we have now not the faintest suspicion.

At present, mathematics and society form two extremes with an abyss between them; by attempting to make them coincide, we run the risk of dwarfing and distorting the social reality. 
In the determination, then, of the sociological laws, we cannot possibly leave man out of account, he must be included as an agent, with his own nature, his powers of intellect and will. These are perhaps data that are partially irreducible and impossible of analysis; but when we look more closely, the inferior sciences actually imply such data. Moreover, there are degrees in the social laws. Some of them express the conditions of a society in which man scarcely acts at all as a man and does little more than follow the promptings of his animal nature. Others have reference to the more strictly human societies, wherein man makes a greater or less use of his reason and energy. The former are in existence before the second, they form the substratum, so to speak upon which human activity works. The animal state is first necessary before one can become a man. Man, however, in a certain measure, controls the animal on which his human nature is based. No doubt this view takes for granted that an idea, as such, may be efficacious. Still, though the immediate sway which an idea holds over matter may be unintelligible, is it so 


\section{THE SOCIOLOGICAL LAWS}

with activity exercised through an infinite number of intermediaries, affecting mind on the one hand, and matter on the other ? Let us not forget that pure mind and pure matter are but abstractions and fancies. When thoroughly understood, mechanism, instead of shutting us in on every hand, constitutes the means at our disposal for acting upon things and for obtaining power over them.

Through the psychic and sociological mechanism, which depend on ourselves, we have a hold on the physical mechanism. A knowledge of the laws of things enables us to control them; consequently, instead of checking our freedom, mechanism makes it efficacious. 


\section{XIV \\ CONCLUSION}

WE have analysed 'the various types of natural laws offered us by the sciences, from the standpoint of these sciences themselves. In the physical laws, we have seen the data supplied to philosophy by the sciences, just as science sees in facts the data supplied to it by nature. In conclusion, we ask ourselves what becomes of human freedom and responsibility, over against these laws, which, to us, represent the nature of things. The problem is a more urgent one now than it was a century ago. When the domain of science, strictly socalled, was not so wide-spread, it was possible to admit that, outside this domain, there was room for freedom. Science, however, is daily gaining both in precision and

$>$ in extent of influence. It is bringing under its sway the very manifestations which seemed most hostile to its influence. 
May it not be, then, that everything, de jure, belongs to it; that everything, consequently, is determined and rendered necessary? As the sense of freedom, in spite of this progress on the part of science, exists, de facto, in the human soul, it is expedient to find out whether there is any contradiction between these two facts, and whether the second must be attributed to illusion resulting from ignorance.

There are weighty reasons why determin- $\checkmark$ ism should nowadays appear more limited than it must have seemed to the men of the past. No doubt the latter saw above them a Destiny which was crushing them; but, as Pascal says, even though he succumbs, man is still nobler than that which slays him, because he knows that he dies. Ancient philosophy, in its classic manifestations, is based on a dualism which prevents determinism from being absolute. Being consists of two elements: truth, the abode of the eternal and the necessary; and phenomenon, impermanent matter, incapable of being definitely fixed in any form. This quality of being ensures the possibility of the contraries, the condition of freedom. 
And so, even in the case of the Stoics, who were rationalistic pantheists, the wise man retains, deep in his soul, the free power to acquiesce in destiny or to resist it. Therefore the ancients maintain that there are two sciences, the second of which cannot be included in the first: the science of being, strictly so-called, perfect and permanent like its object, and the science of becoming, imperfect and impermanent like becoming itself.

Now, the essential characteristic of modern science is a tendency to do away with this duality. Its fundamental idea, formulated by Descartes, consists in admitting that there is a point at which the sensible coincides with the mathematical, and becoming coincides with being; that things are not more or less imperfect copies of transcendent paradigms, but rather particular determinations of the mathematical essences themselves. Hence, we have an altogether new compass or range attributed to inductive reasoning. In Aristotle's mind, no empirical knowledge, as such, might lay claim to universality and necessity. Experience was inevitably limited to the relative. But if all the pro- 
perties of things are, in their essence, mathematical, even experience may attain to the necessary, provided it succeeds in discerning and unravelling or extricating this interior warp and woof of reality. Distinct as they were in the minds of the ancients, mathematics and experience remained, the former, transcendent; the latter, uncertain. Closely united, they are the foundation of a complete science of sensible reality itself. Mathematics imparts to science, necessity; experience imparts conformity with facts. Such is the root of modern determinism. We believe everything to be necessarily determined, because we believe everything, in essence, to be mathematical. This belief is the spring, manifest or unperceived, of scientific investigation. What we have to find out is whether this is a truly constitutive principle, or simply a regulating principle and a guiding idea. Does science prove that the basis of things is exclusively mathematical, or does it only assume this?

Modern determinism is based on the two following assertions: (I) mathematics is perfectly intelligible and is the expression of an absolute determinism; (2) mathematics 
applies to reality in the most precise manner; de jure, at all events, and in the essence of things.

Let us begin with the first of these two theories. It regards mathematics as simply a special development of logic. Now, logic, real logic, at any rate, including the theory of concept, judgment and reasoning, actually presupposes data that are irreducible to a strictly analytical relationship: the only type of perfect intelligibility. Concept, judgment and syllogism have ever given rise to controversy. The reproach of barren tautology, as regards their importance, is removed only by the introduction of considerations that have nothing to do with pure logic. Such is the notion of the implicit and the explicit, which meets the difficulty, in a fashion, though only by appealing to the obscure metaphysical distinction between act and potency.

$\Gamma$ While logic contains elements that cannot be reduced to pure thought, mathematics contains a greater number of these elements. In spite of all their efforts, mathematicians have not succeeded in bringing mathematics within the compass of simple logic. Descartes, by means of his theory of intuition and deduc208 


\section{CONCLUSION}

tion makes a radical distinction between mathematical method and syllogistic reasoning. Mathematical knowledge, to his mind, compasses principles that have a content; it proceeds from the simple to the compound, which logic does not do. Under the various names of synthetic d priori judgments, postulates, definitions, axioms and fundamental facts, philosophical mathematicians admit, either as coming from experience or from the intellect, given and inscrutable principles. $]$ In effect, mathematics has been established and is moving towards perfection by a process of generalization which consists in imagining axioms and definitions that allow of the development of demonstrations with the utmost possible continuity and the fewest possible gaps. How are we to affirm that principles thus received for the needs of the cause are all necessary and perfectly intelligible? The philosophical analysis of principles and of mathematical methods reveals therein many a contingent determination, many an artifice accepted mainly because it is successful.

And so mathematical necessity itself is no longer unconditioned in our minds, as it may 
NATURAL LAW IN SCIENCE AND PHILOSOPHY

have been in the minds of the ancients, who regarded mathematics as entirely a priori.] On the other hand, this necessity has lost the aesthetic character it possessed for the Pythagoreans and the Platonists. To us, it is a blind and brutal necessity which goes straight ahead, without either goal or check. Is this necessity, such as it is conceived to be, really part and parcel of things? Is the complete fusion of mathematics and experience, the object of modern science, effectually realized ? Does it appear as though some day it will have to be realized ?

To enable mathematics and experience to become closely united, it has been assumed that everything given may be split up into two elements incapable of permeating each other: movements and states of consciousness ; and that the first of these two elements is, as regards knowledge, the legitimate substitute of the second. In so far as things may be looked upon as consisting of movements, they fulfil the conditions of a mathematicoexperimental science.

Can this separation-so precise and strict in philosophy-between quantity and quality, be accurately realized in the sciences? This 
is more than we can affirm. [Mechanics, the concrete science which must be the basis of all the rest, offers elements that are irreducible to pure mathematical determinations; it is incapable of entirely transforming its experimental data into rational truths. Known by experience alone, the most general connexions between things remain, so far as we are concerned, radically contingent, as Newton said. Why are bodies attracted to each other in the ratio of their mass and not of the square of their mass? This is a fact, nothing more. Celestial mechanics, after all, implies the very idea of natural law, in so far as this law is distinct from purely mathematical relations, i.e. in so far as it brings together two terms, one of which can in no way be deduced from the other.]

Moreover, it would be incorrect to say that mechanics, of itself alone, de jure, at all events, constitutes the entire science of the real. For, in the present state of our knowledge, science is not one, it is multiple. Science, regarded as including all the sciences, is but an abstraction. That which is given consists of sciences, each 
of which, whilst remaining connected with the rest, has its own distinctive aspect and evidence. In proportion as we advance from the study of the motions of the heavenly bodies-the most external reality with which we are acquainted - to the study of life and thought, the postulates required are the more numerous and inaccessible.

Physics, by regarding work as superior to heat, actually makes an open appeal to the notion of quality. Chemistry is based upon the postulate that elements of different kinds exist and are maintained in existence. The reflex act of biology is no simple mechanical reaction, for it has the property of ensuring the conservation, evolution and reproduction of a determinate organization. Psychic reaction is something more, since it tends to provide an individual with the science of things, i.e. the knowledge of laws, and thereby with an indefinite power to utilize them for ends laid down by himself. To sum up, in sociology, the action of environment is not sufficient to explain phenomena ; we must introduce man, with his knowledge and prejudices, his power of sympathy. 


\section{CONCLUSION}

with other men, and his ideas of happiness and progress, justice and harmony.

Thus, the objects of the various sciences are not wholly permeated by mathematics, and we look upon the fundamental laws of each science as the least defective compromises that the mind has succeeded in finding for bringing together mathematics and experience. Moreover, we must distinguish between the physical sciences, which readily unite with mathematics, and the biological sciences, $\checkmark$ for which this union is far more artificial. In the former, man himself limits his field of investigation; he purposes to take into consideration only a certain order of manifestations of nature-that which is amenable to measure and number-and to neglect the rest. Owing to this partially arbitrary delimitation, we have to deal with something that sensibly admits of mathematical determination. In the biological sciences this method may still be employed; but here we are manifestly leaving out of our investigation the best and most characteristic part of the phenomena.] The more we resolve to grasp or understand being in its concrete reality, the more we must be con- 
tent with observing and inferring, and must refrain from using mathematical analysis. Thus the mathematical form gives the sciences a certain character of abstraction. The concrete living being refuses to be confined therein.

In a general way, then, there are two kinds of laws: the first, which are more akin to mathematical conjunction and imply considerable elaboration and purification of concepts; the second, which are nearer to observation and induction, pure and simple. The former express a rigorous, if not absolute, necessity, but they remain abstract and incapable of determining the details and the mode of effective realization of the phenomena. The latter treat of the details and the relations which complex and organized wholes have with one another : consequently they are far more determinative than the former; but as they have no other basis than experience and connect together wholly heterogeneous terms, they cannot be regarded as necessitative. Possible prediction does not imply necessity, since free acts may admit of it. Thus, necessity and determination are distinct from each other; our science cannot blend them into one. 
To sum up, on the one hand, mathematics is necessary only with reference to postulates whose necessity cannot be demonstrated, and so is only hypothetical after all. On the other hand, the application of mathematics to reality is only approximate, and seems as though it could be nothing else. Under these conditions, what is the doctrine of determinism? It is a generalization and a passing over to the limit. Certain concrete sciences approach mathematical rigidity; the inference is that they are all destined to attain to the same perfection. The distance that separates us from the goal may be increasingly lessened: the inference is that it may become nil. This generalization, however, is a theoretical view. As a matter of fact, the distance between mathematics and reality is not on the point of being abolished; and, if it is lessening, the number of intermediaries which would have to be intercalated to effect the junction of the two, appears more and more to be infinite. Historically, the idea of reducing the real to the mathematical is due to ignorance of this incommensurability of the real and of the mathematical ; iguor- 
ance, in this case, has had good results; for less eagerness would have been shown in making for a goal known to be inaccessible. The application of the Cartesian idea not only demonstrated its fertility, it also transformed into a transcendent ideal what, to Descartes, was a principle and a starting-point.

But if we compare with the present state of science the testimony of consciousness in favour of freedom, we shall find this testimony far more acceptable now than it was in Cartesian dualism, for instance. When things were reduced to matter and thought, to assume man to be free and his freedom to be efficacious, was to admit that spirit, as substance, moves matter, as discrete substance. Now, this is incomprehensible, whether we assume that spirit creates motor force, or admit that what is not itself motion can directly determine motion. Science, however, by no means establishes the reality of this dualism. It rather shows us a hierarchy of sciences, a hierarchy of laws, which we can compare with one another but not blend into a single science of external things and into a single law. It shows us, besides, along with the relative heterogeneity 
of laws, their influence upon one another. The physical laws involve living beings, and the biological laws combine their action with that of the physical laws. In presence of these results, we are led to enquire whether thought and motion, along with the abyss that separates them, might not be our mode of bringing things clearly before the mind, rather than their real mode of being. Motion, per se, it would appear, is but an abstraction, as also is thought, per se. What exists are beings, whose nature is intermediate between the pure idea of thought and of motion. These beings form a hierarchy, and action moves amongst them from above, downwards, and from below, upwards. Spirit moves matter neither immediately, nor even mediately. There is no crude matter, however, and what constitutes the being of matter is in communication with what constitutes the being of spirit. That which we call the laws of nature is the sum total of the methods we have discovered for adapting things to the mind, and subjecting them to be moulded by the will I In the beginning, man saw nothing but supernatural caprice and arbitrariness every- 
where. Consequently, the freedom he attributed unto himself had nothing on which it could lay hold. Modern science showed him physical law everywhere, and he imagined he saw his freedom being engulfed in universal determinism. A correct idea, however, of the natural laws, restores him to true self-possession, and at the same time assures him that his freedom may be efficacious and control phenomena. Of things without and things within, the latter alone, said Epictetus, depend on ourselves, and he was right at the time he spoke. The mechanical laws of nature, revealed by modern science, form, in reality, the chain that binds the without to the within. Instead of being a necessity, they set us free; they enable us to supplement, by active science, that state of contemplation in which the ancients were plunged.

THE END

Printed by Butler \& TANNer, Frome and London. 





\section{YC 22487}

GENERAL LIBRARY - U.C. BERKELEY

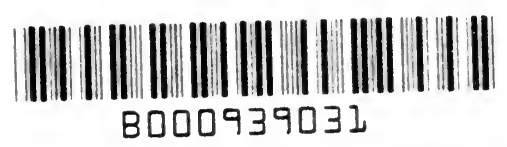

$\therefore \quad$. 
